\title{
INCAUTACIONES: APORTACIONES DOCUMENTALES PARA UN INFORME DEL PATRIMONIO ECLESIÁSTICO EN EL SIGLO XIX
}

\author{
POR \\ Ma Dolores García GómEZ \\ Universidad de Alicante
}

RESUMEN

En el presente artículo se estudian y publican los dos informes remitidos en 1869 y 1870 para la incautación de archivos bibliotecas y objetos de arte del clero. Además de las disposiciones del gobierno, esta documentación lo que nos permite conocer es el valor de los manuscritos que se conservan en la mayor parte de las provincias españolas, aunque su validez va a estar en función de la preparación y la capacidad de los informantes locales y las facilidades que tienen para acceder a los fondos.

PALABRAS ClAVE: Bienes eclesiásticos, siglo XIX.

\begin{abstract}
At this article are studied and published the two reports sent in 1869 and 1870 for the confiscation of archives, libraries and objects of art of the clergy. Besides the dispositions of the government, this documentation shows the value of the manuscripts that are preserved in the majority of the spanish provinces, although their validity are connected with the preparation and the ability of local informants and the facilities they have to accede to the resources.
\end{abstract}

KEY WORDS: Ecclesiastic properties, XIXth century.

El día 8 de marzo de 1869 una comisión formada bajo la presidencia de d. Antonio $\mathrm{M}^{\mathrm{a}}$ García Blanco y la asistencia de los sres. García Rosell, Bardón,

Incautaciones de bienes eclesiásticos Hispania Sacra 57 (2005) 
Rico y Sinobas, Gayangos, y como secretario d. Vicente Vignau ${ }^{1}$, se reunían en sesión preparatoria para examinar los expedientes de incautación de archivos, bibliotecas y objetos de arte del clero, llevados a cabo en la mayor parte de las provincias españolas, que continuaron a lo largo de la primera mitad de ese año. Esta sesión ratificaba y perfilaba los acuerdos tomados un año antes, en Decreto del 1 de enero de 1868, desde el Ministerio de Fomento bajo el mandato de su titular D. Manuel Ruiz Zorrilla, para iniciar la valoración e inventario de las pertenencias y objetos de interés en posesión del estado eclesiástico, con el fin de rescatar aquellos bienes que se consideraba que eran patrimonio cultural de la nación.

La orden de incautación de todos los archivos, bibliotecas gabinetes y demás colecciones de objetos de ciencia, letras y artes que posea el clero, de 1 y 18 de enero de 1869, las declaraba como patrimonio del Estado en todo el territorio nacional. Se llevó a cabo la medida a lo largo del 1869, algunos informes de 1870 excusan las demoras en la ejecución y en 1871, y desde posiciones más generales, se intentaron replantear las iniciativas tan parcialmente llevadas a termino hasta entonces para mejorar la precaria situación de los valiosos documentos contenidos en los archivos y bibliotecas nacionales.

En los informes resultantes de aquellos pesquisas, se presentaron, primeramente, un extracto o informe previo junto con la lista de los individuos que habían llevado a cabo las primeras visitas, junto con el recuento de las bibliotecas, los archivos y los objetos artísticos más notables que estaban en las manos del clero, pasando a continuación, en un segundo informe, a la catalogación por orden alfabético de los que se habían podido realizar, intentando detallar el contenido de esos fondos documentales en cada una de las provincias ${ }^{2}$. La información que estas descripciones ofrecen, en la medida de las limitaciones a que continuamente hace referencia, supone un rica información docu-

1 Los titulares de la Comisión acreditaron su conocimiento y experiencia en los temas que se habrían de debatir con los títulos que exponen en la sesión preparatoria: su presidente, d. Fermín Caballero, Académico de Historia, Ciencias Morales y Políticas; d. Cayetano Rosell, , individuo de la Academia de la Historia, Director de la Escuela de Diplomática y de la sección de Manuscritos de la Biblioteca Nacional; d. Lázaro Bordón, catedrático de la Facultad de Letras; d. Manuel Rico y Sinovas catedrático de la Facultad de Ciencias; d. Jose M $^{\mathrm{a}}$ Escudero de la Peña profesor de la Facultad de Ciencias y Secretario General del Cuerpo de Bibliotecarios, Archiveros y Anticuarios. No aparecen sin embargo en todas las sesiones ni el Presidente ni el secretario - d. Fermín Caballero y d. Jose $\mathbf{M}^{\mathrm{a}}$ Escudero de la Peña-, que son sustituidos por d. Antonio Ma García Blanco, Decano de la Facultad de Filosofía y Letras y Catedrático de Lengua Hebrea de la Universidad Central y d. Vicente Vignau, en calidad de secretario, junto con d. Pascual de Gayangos, catedrático de Lengua Árabe y Académico de la Historia.

2 Archivo General de la Administración. [A.G.A.] Educación. Cajas 6813-6814- 6815- 68166817. Actas, Expedientes e Informes Provinciales de las Incautaciones de Archivos, Bibliotecas y Objetos de arte del Clero, ordenadas por Decreto del Ministerio de Fomento. Enero, 1868. 
mental de buena parte del patrimonio artístico nacional que pertenecía al estado eclesiástico, que puede facilitar tanto el conocimiento de los fondos documentales actuales como de los desaparecidos.

Es evidente que tanto en el extracto previo como en el detallado, las sucintas descripciones - en la mayor parte de los casos-, ponen de manifiesto el desconocimiento de la labor que se habían fijado llevar a cabo. Ante su resultado, la propuesta inicial de inventariar el patrimonio religioso nacional, pronto tuvo que ser reconsiderada por los artífices del proyecto, a la vista del desconcierto e impotencia de los comisionados encargados de llevar a fin esa tarea prometéica, en la que estaba en su contra, entre otros impedimentos, la limitación del tiempo propuesto para su consecución, la poca preparación técnica de los encargados, el estado evidente de abandono y desidia de gran parte de esos fondos 3 , y sobre todo y como es lógica, la falta de colaboración del hasta entonces dueño de aquel patrimonio, la Iglesia, que aunque en buen número de los casos lo tuviese arrinconado e ignorado, era suficiente la demanda de su expolio para cerrar las filas y poner trabas a la petición, a la orden, de información o ayuda ${ }^{4}$. Evidencia esta situación las respuestas de los comisio-

3 Sirve de ejemplo en la mayor parte de las administraciones que excusaron la falta de presentación de datos, la comunicación que se envía a Fomento, desde Albacete, tras el informe que d. José $\mathrm{M}^{\mathrm{a}}$ Jiménez, jefe de la sección de Fomento de esa provincia, ...la mayor parte de los legajos registrados son documentos de censos, cuentas simples de la Administración interior de los Conventos, apuntes de cargas y mandas pias, expedientes de competencias religiosas, y únicamente algunas en el orden que lo expresamos, creemos que arrojarían noticias útiles, pero solo ofrecian en un perverso estado inventarios, cuadernos de efectos y papeles sueltos y algunas escrituras de posesión a favor de los conventos de fincas rústicas y urbanas.

$4 \mathrm{El}$ informe acerca dela conducta del clero en la incautación señalaba que ...casi todos los obispos han protestado del mencionado decreto, apoyándose en los cánones de la Iglesia y rechazando algunas apreciaciones, pero ninguno ha producido queja sobre el modo que las autoridades lo han llevado a cabo....si bien en algunos cabildos, Navarra, Santander, Vich y otros se han distinguido por la resistencia pasiva oponiéndose a las prescripciones del Decreto. Aunque este informe señalaba solo los cabildos de esas poblaciones, en otras hubo también oposición abierta al registro: en Murcia no se pudieron inventariar los bienes de la Catedral ni de las parroquias, León emite inmediatamente una instancia de la Diputación a las Cortes pidiendo la devolución de lo incautado, Huesca pide igualmente la devolución del material científico (aunque solo consiguieron los objetos de Física y Geografia), e incluso en alguna de ellas, como en Zamora, se comunica de la sospecha de un secuestro de los libros por parte del cabildo, que los habían escondido en un local cercano a la Catedral. Casos citados como muy especiales son los referentes a León y sobre todo a Valencia, en las que estuvo sin determinar a lo largo de los meses el estado de las incautaciones: para remediarlo se elevó una moción con una lista de argumentos que remediara aquel desorden, que se sintetizaron en catorce resoluciones, que el comisionado D. Miguel Velasco y Santos debía llevar a cabo; de todas ellas es importante resaltar la del traslado de todos los libros que pertenecieron a la Catedral y se destinaron a la biblioteca de la Universidad, que no obligaba sino a la reseña y nota de la cuantía de los volúmenes trasladados, respetando sin embargo las bibliotecas del Arzobispado y del $B^{\circ}$ Rivera en sus lugares respecti- 
nados en la mayor parte de los informes, con el resultado de patrimonio negativo o de pedir un aplazamiento para una nueva revisión, pese a ser los bienes que enumeran, de reconocida riqueza patrimonial.

En diez disposiciones se detallaba el procedimiento de las incautaciones enviadas a todos los todos los Gobernadores de las 49 provincias de la nación, delegando en los individuos del Cuerpo de Bibliotecarios, Archiveros y Anticuarios la autoridad para llevarla a cabo, previniendo su impunidad en cualquiera de sus decisiones, en un considerado gesto, y exigiendo el mayor respeto por las decisiones que tomasen estos comisionados.

En la circular presentada para la sesión de trabajo, se precisaba la necesidad de distribuir a cada provincia el informe elaborado acerca de los bienes de la misma, con especial atención a que llegase por igual a las corporaciones eclesiásticas que a las entidades administrativas, custodios unos y responsables los otros de los bienes que en ese momento reclamaba el Estado, y proceder a continuación a su incautación. Sé conminaba a los responsables de estas incautaciones a llevarlas a cabo con energía y actividad sin olvidar el tacto y la mesura que avaloran el prestigio de la autoridad. Se pedía igualmente resolver las dificultades pidiendo responsabilidades a quien correspondiese, sin distinción de estado ni clase. Ese tono exigente respondía sin duda al plan de desamortización que iniciaba el gobierno liberal del general Serrano, que según se proclamaba en la revolución de septiembre de 1868 , se proponía llevar a cabo la secularización de la riqueza literaria, artística y científica patrimonial.

Ante el estado de abandono de ese patrimonio nacional, el Ministerio de Fomento, en Decreto de 1 de enero de 1869, resaltaba el estar al frente de un gobierno que se preciaba de ilustrado, y tras exponer con dramatismo el estado de conservación de la riqueza histórica patrimonial, del que hacía culpable al principal guardián de la misma, la Iglesia, informaba de las garantías que esos bienes tendrán con las medidas de vigilancia que su gobierno tenía programadas. Las desamortizaciones de 1834 y de 1856, que calificaban de limitadas ambiciones y cortos intereses, sin logros efectivos, ya planteaban lo que en ese momento se pretende llevar a cabo, obligando a su cumplimiento.

Un año después, en enero de 1870, ante las quejas por la clausura, por el sellado de buen número de archivos eclesiásticos, se informa desde el propio Ministerio de las demoras que sufrían las gestiones que tan prestamente se iniciaron. Conscientes de no haberse llevado a cabo en ese tiempo las copias y testimonios de sus contenidos, y ante las presiones de corporaciones o de particulares que habían de hacer uso de dichos archivos, el Ministerio dió permi-

\footnotetext{
vos, dado su carácter abierto a la consulta pública, circunstancia especial entre todas las incautaciones que favorecía la excepcionalidad de las distinciones que obtuvo.
}

Incautaciones de bienes eclesiásticos

Hispania Sacra 57 (2005) 
so, para que en los casos que se necesite y siempre llevándolo a cabo un comisionado ante un representante de la autoridad civil, y si gusta, otro de la eclesiástica, pudieran abrirse esos archivos.

En esa situación gestora, protectora, se hacía hincapié en la intención de una mayor preocupación por el estado y futuro de los archivos que por el de las bibliotecas, aunque se mantuvieran en una relación conjunta todos los bienes artísticos o documentales. Es posible que ese amplio frente de expropiación todavía diera lugar a una mayor tensión, como parece desprenderse del gran número de protestas que suscitó. Las quejas por parte de las catedrales fueron airadas, refiriéndose principalmente a que les eran incautados documentos que no tenían carácter histórico, pues atendían al régimen interno de la iglesia ${ }^{5}$ : la contestación del Gobierno fue dar a los documentos una clasificación en la que solo una parte de ellos podían ser considerados de régimen interno ${ }^{6}$. Se quejaba también el clero de que se habían intervenido e inventariado las alhajas, los cuadros, los objetos de arte, recibiendo la contestación de que solo en ese reconocimiento se podrían salvaguardar en el futuro de sustracciones o pérdidas, cuando por otra parte, se proyectaba recoger los objetos o cuadros que no estuviesen expuestos al culto público. No se dejaba de censurar la conducta de casi todos los obispos, que se habían opuesto a las medidas apoyándose en los Cánones de la Iglesia, e incluso se prevenía una circular para que en los casos de resistencia, los gastos que se originasen por la demora que acarrease esa resistencia, fueran sufragados por el clero.

La comisión formada para revisar los informes de cada una de las provincias y presentar un primer informe o extracto del que se llevaría a cabo a continuación, acordó reunirse dos veces por semana, para ir estudiando los casos de los informes que periódicamente les iban haciendo llegar desde las distintas poblaciones en donde se llevaban a cabo las incautaciones. En reuniones celebradas desde el 20 de marzo de 1869 - continuadas en 30 de marzo, 3 de abril, 6 de abril, 10 de abril, 13 de abril, 17 de abril, 24 de abril, 1 de mayo, 4 de mayo, 8 de mayo, 11 de mayo 16 de mayo y 29 de mayo-, poco más de dos meses, llevó a cabo su cometido con el atento reconocimiento de los informes que recibían, que motivaron el elogio por el buen hacer de los individuos que se habían encargado de realizarlos, calificados como "todos competentes, y

5 Constituyó un duro frente de oposición la pertenencia de los títulos de propiedad de fincas desamortizadas, que la Comisión alegaba ...pertenecen a la Nación y a los compradores de estos bienes.

6 Dividían estos documentos para considerar los incautables en : $1^{\circ}$ privilegios reales y comisiones apostólicas, que por haber caducado ya son de dominio histórico; $2^{\circ}$ títulos de propiedad de las fincas desamortizadas, que pertenecen a la nación y a los compradores de estas; $3^{\circ}$ papeles referentes a diezmos, rentas y administración de las Iglesias, que por su nuevo modo de ser ya no afectan a las mismas; $4^{\circ}$ solo las actas capitulares y previsión de prebendas o constituciones sinodales pueden considerarse documentos propios de régimen interno... 
solo en algunos de los casos que se habían tenido que encargar de hacerlo individuos nombrados por las autoridades locales, adolecían de precisión". La lista de los comisionados no ofrece el nombre de todos los encargados de llevar a cabo las incautaciones, informándose en algunos casos de no constar el mismo en el resultado de las mismas. El acta de las sesiones atendía a valorar los objetos o documentos más relevantes de cada uno de los informes, y daba el visto bueno para el traslado propuesto. También se trataban los capítulos de las costas por los traslados, así como los roces y disputas surgidas por algunas de las incautaciones 7 . En junio - sin fecha del día- de 1870, una escueta sesión precisa unas últimas reclamaciones, y un mes después, en 23 de julio, se consideraron todas valoradas y se acuerda posponer la siguiente reunión hasta una nueva orden.

Los nombramientos de los encargados de llevar a cabo la valoración e informe los asignaban, según las circunstancias de cada caso, el Ministro de Fomento, los gobernadores o los alcaldes de los respectivos lugares. Entre los designados están, por Alicante, d. Román García y Aguado; Almería, el arquitecto de la provincia; en Ávila, d.Vicente Vignau; Baleares, d. Bartolomé Muntaner; en Barcelona, d. Antonio Bofarull; Vich, d. Mariano Aguiló, Cardona, d. Juan Riva; Manresa d. Ángel Rivas; Burgos d. Francisco Bermúdez; Bibriesca, d. Benigno de Arce; Coria, d. Vicente Maestre; Plasencia, d. Francisco Ruvi; Jerez de la Frontera, d. Manuel Bertemati; Ceuta, d. Teodoro Gonzalez; La Laguna, d. Martín Bello; Gran Canaria d. Tomás de Iriarte; Córdoba, d. Julio Aguilar y d. Luis $\mathrm{M}^{\mathrm{a}}$ Ramírez Deza; Coruña, d. Manuel Villarmil; Gerona, d. Joaquín Carreras; Villabeltrán d. Fernando Vila; Granada, el Jefe de Fomento; Guadíx, d. Francisco Fernández; Alcalá, d. Carlos Santamaría; Siguenza, d. Francisco Navarro; Pastrana, d. Manuel García; Huelva, Comisión de Monumentos; Huesca y Jaca, d. Mateo Lassala; Tamarite d. Mariano Purroy; León d. Ramón Álvarez Braña; Mondoñedo, d. Jacinto Romualdo; Lugo, d. Manuel Gómez de las Heras; Ronda, d. Cándido González; Lorca y Murcia d. Cándido Albacete; Pamplona, d. Pablo Ibarregui; Roncesvalles, d. Cayo Joaquín López; Tudela, d. Antonio San Miguel; Orense, d. Juan Leonato; Oviedo, d. Juan Rodríguez; Ampudia, d. Juan Francisco Lobos; Salamanca, d. Domingo Doncel; Santander, d. Antonio Feliú García; Segovia, d. Antonio Borregón; Soria, d. Lorenzo Ramos; Tarragona d. Manuel Talavera y d. Buenaventura Hernández; Teruel, el Jefe de Fomento, Toledo, d. Eduardo Mariategui, d. José Octavio de Toledo y d. José Escudero de la Peña; Valencia d. Miguel Velasco; Játiva, d. Ramón Barrús; Valladolid, d.

7 En algunos casos se habían suscitado curiosas reclamaciones, como la de el Sr. Barón de Escriche, que reclamaba ...la devolución de la cabeza natural del Sr. D. Gil Sanchez Muñoz, electo Papa en 1423, por ser de su propiedad y tenerla en depósito en el oratorio de la Sala Capitular de la Catedral de Teruel. 
José Lomoza; Zamora, d. Tomás Garnacha; Toro, d. Juan Rodríguez; Zaragoza, d. Andrés Domecq.

De las ciudades de Badajoz, Roa, Peñaranda, Castellón, Segorbe, Ciudad Real, Besalú, Ripoll, San Feliú, Guipuzcoa, Jaén, Jaca, Lérida, Logroño, Málaga, Cartagena, Palencia, o Vizcaya no consta el nombre del comisionado. La práctica total de los informes los llevaron a cabo los archiveros-bibliotecarios de las catedrales o instituciones en donde se llevaba a cabo la incautación, en algún caso se cita en su lugar a un profesor de instrucción primaria (Manresa), a un representante de la Academia de la Historia ( Jerez de la Frontera), un canónigo ( Santander), un abogado (Pastrana), un ingeniero civil (Segovia), la propia Comisión (Huelva), o al Jefe de la sección de Fomento ( Cuenca, Granada).

Las disposiciones dictadas por el Ministro de Fomento habían sido exigentes en todos los aspectos que podían dar lugar a la demora de la puesta en marcha del plan de incautación, especialmente en los temporales - debían reunirse los archiveros-bibliotecarios junto con la autoridad civil de cada lugar en el perentorio término de una hora, y tras el nombramiento de los designados pasarían a tomar inmediata posesión del cargo de inmediato bajo ningún pretexto ni motivo-, y en los de la seguridad de los bienes inventariados: para esta seguridad se disponía que quedaran en poder de las autoridades todas las llaves de puertas, armarios, arcas, mesas etc, no debiendo abrirse sino los muebles que contuviesen los inventarios. Ratificaban ese estado de seguridad la firma conjunta de la autoridad civil correspondiente, el comisionado, un individuo de la institución clausurada y otro representante del clero, y del resultado del inventario, la autoridad civil podría exigir la confrontación con los bienes y hacer que fuera firmada por la autoridad eclesiástica correspondiente.

Una vez llevada a cabo la información de los valores inventariados, se valoró desde la comisión la gestión como un notable enriquecimiento bibliográfico, pues se habian dado a conocer multitud de incunables y libros raros y curiosos; de un enriquecimiento paleográfico, por la cantidad de códices y documentos paleográficos, y en fin, en el ramo de la historia por presentar datos relaciones y detalles desconocidos hasta ahora. Acerca del enriquecimiento bibliográfico se insistía en el nulo uso de los libros que estaban en las bibliotecas de las catedrales, los canónigos de muchas de las cuales incluso desconocían que las hubiera en su catedral, tal era el relegamiento y olvido en cuartos y trasteros abandonados 8 ; en las que no ocurría así, de las que pretendían que su posible acceso fuera público, se señalaba que siendo muchos libros antiguos o

8 De las catedrales de Valencia y de Ávila se señala que había indicios evidentes de que ... la mayor parte de los libros no habian sido abiertos jamás, lo cual no tiene mucho de extraño pues en ellas gran parte de los libros incautados pertenecían a la primera época de la imprenta, y no sirven por la dificultad de su lectura para el común. 
incunables, por su caligrafía era imposible la lectura para individuos que no fueran especialistas, hecho que reforzaba la intención de su expropiación.

En mayo de 1871, dos años después de la programación de la Orden, no se había resuelto nada acerca del destino de los bienes incautados. En esta fecha se retomaron las iniciativas por parte de la comisión del Ministerio de Fomento encargada desde los inicios de llevarlo a cabo, pidiéndose de nuevo, como en aquella, que se diera idea del valor y mérito artístico e histórico de los documentos y papeles que existieran en los archivos nacionales, parroquiales y de las catedrales, especificando el número de legajos y si contenían pergaminos.

Se renovaron las excusas y las quejas por el tiempo transcurrido en ejecutarlos, se pide disculpas por el método con que se realizaron: pocos, oscuros e insuficientes. La propuesta gubernamental, de mayo de 1871, era de archivar la documentación incautada en el Archivo Histórico Nacional como ya se había hecho desde su creación en las anteriores desamortizaciones, merced a la diligencia de la Real Academia de la Historia y a la eficaz protección del Gobierno. Se citaba la ineficacia de la actuación y protección de los empleados de Hacienda, custodios hasta ese momento de los fondos incautados, a pesar de su buena voluntad, por lo que sería conveniente eximirlos de ese trabajo. Se preveía, antes de su traslado al Archivo Histórico, una primera catalogación y ordenación de los fondos in situ, que implicaba la disposición de unos trámites que dispongan el traslado de individuos del Cuerpo de Archivos y Bibliotecas a las ciudades donde se ha de llevar a cabo. Para excusar el gasto de las dietas que conllevara esa medida, se ponía el ejemplo los beneficios que en la anterior y primera incautación se logró, en la que se consiguió la Real Academia de la Historia reunir mas de cien mil documentos y cerca de doscientos códices que hoy guarda el Archivo Histórico...

\section{INFORME DE LA INCAUTACIÓN.}

El Informe ofrecía en primer lugar un listado extracto por provincias, en el que se detallaban de las localidades reconocidas en cada provincia, el resultado de la incautación y el destino recomendado para los bienes incautados. Un segundo informe los catalogaba precisando los fondos reconocidos. En atención a ese orden reproduciremos primeramente los resultados del primer Informe, o Extracto, aunque no lo hagamos sino en su contenido.

En el Extracto del Expediente General se reconocen como las bibliotecas más notables de la nación, por su cuantía o riqueza, las de la Colegiata de san Nicolás de Alicante, las episcopales de Orihuela, Palma y Toledo, las de las catedrales de La Laguna en Canarias, Santiago, Guadix, Pamplona, Salaman- 
ca, Toledo y Valencia, y la del monasterio de Uclés; los archivos de Cuenca, Huesca, León, Salamanca, Toledo, Valencia y Valladolid son los señalados como principales: pero hay que decir que no todas las bibliotecas ni todos los archivos así señalados se corresponden con los que luego explicita el catálogo. Las diferencias en los resultados de uno y otro informe se refieren a varios ámbitos, el principal es el de no estar incluidas en el catálogo sino una parte de las provincias que se habían informado en el extracto, - ejemplo importante son las de Zaragoza y Zamora-, y en algún caso el de no dar en éste, lógicamente más completo, datos que adelantaba el informe, por lo que parece probable que uno y otro estudio pudieran realizarse sin estar finalizados ni cotejados ambos. En algunos casos retrasa la información, como en los de Toledo o Valencia en los que se reclama una comisión especializada.

Algunos datos podemos recoger de los informes, especialmente útiles para reconocimientos posteriores. Al resultado de que informa el extracto acerca de las más importantes bibliotecas de la nación, Alicante, Orihuela, Palma y Toledo, hay que añadir las que describe el catálogo, las de Ávila, Jerez de la Frontera, Córdoba, Granada, León, Medina del Campo en Valladolid y Navarra y en esa provincia también la de Roncesvalles. La cuantía de los fondos varía mucho entre ellas y casi no las hace equiparables atendiendo a esa importancia numérica. La mayor de todas en la de Córdoba, con 12.000 volúmenes, seguidas de las de Navarra o Roncesvalles, con casi 8000 volúmenes cada una; las de Ávila, Alicante y Jerez están alrededor de los 5000 volúmenes y de las del resto en las que viene consignada su cuantía, León, Canarias, Coruña, Guadix, Huesca, ninguna sobrepasa los 1500 volúmenes, a excepción de la de Medina del Campo con 2253. En otro buen número de poblaciones no se daba noticia alguna de su biblioteca, bien porque no se haga alusión siquiera a su existencia o porque incluso se especifique que hay algunos libros que por su mal estado no merecen atención. De la biblioteca del Monasterio de Uclés, que el extracto señalaba como de importante cuantía, el catalogo no hacía otra alusión que la de "que en tiempos fue importante."

Frente a la imprecisión de este dato, el de la cuantía de los ejemplares a incautar, que a primera vista debía haber primado en una valoración de expropio, algunos otros merecen señalarse, aunque la impresión general es la de una enumeración cuantitativa, llevada a cabo por comisionados que tenían poco conocimiento bibliográfico, diplomático y en general documental. Ante la descripción de lo que encuentran en las bibliotecas que los comisionados van visitando, se pone de manifiesto que quizás no pudiesen o quisiesen acometer la tarea de un recuento, por los ya dichos inconvenientes de falta de tiempo, incomodidad y suciedad de los locales, o pocas facilidades por parte de los custodios para que ese recuento fuera posible, y es cierto que la totalidad de los resultados que ofrecen acerca de esa cuantía los extraen de las propias biblio- 
tecas visitadas, en las que los responsables de las mismas, encargadosbibliotecarios, o encargados-archiveros, les informaban de su número. Sin embargo algunas pesquisas, algunos datos curiosos enriquecen la información acerca de la composición de la biblioteca, en casos fiel reflejo del encargo que debía primar en la incautación, el valor de los libros documentos u objetos, y otras veces fruto del conocimiento que algunos encargados-bibliotecarios ofrecen de las mismas - en Cádiz, Canarias, Córdoba o desde luego en Barcelona-, circunstancia que suele ir acompañada del nombre del bibliotecario, en los casos de las de Alicante, Baleares, Santander o Córdoba.

Si en la descripción de las bibliotecas la información del número de volúmenes no es constante, la de los temas o áreas que la componen tampoco se da en cada una de las que se informa de su contenido: se hace en las de Orihuela, Ávila, Baleares, Jerez de la Frontera, Canarias, Santiago de Compostela, Guadix y Sigüenza; los casos en las que además de informar de los temas se detallan los títulos de las obras solo se dan en las de Orihuela, Guadix y Sigüenza. Sin embargo aparece con frecuencia la llamada de atención a un determinado título, para valorarlo económicamente, resaltando que debe ser tenido en cuenta por su antigüedad o rareza. En estos casos la descripción tipográfica del volumen enriquece el informe general, pero se pone de manifiesto que esa evaluación es solo un aviso del que los comisionados estarían prevenidos, y no el resultado de un cuidadoso o sabio conocimiento. Apoyando esa intención se describen igualmente los manuscritos, incunables y códices, pero haciendo hincapié en el valor que a tal o cual pieza daría un anticuario. Acerca del origen de las bibliotecas visitadas en muy pocos casos se informa de las donaciones de particulares que las originaron, pero es reseñable las citas de las formadas con la aportación de los colegios de jesuitas, después de la expulsión de 1767, la de Baleares la del colegio de Pollensa, en Córdoba las de los colegios de Córdoba y el de Montilla, en León el del colegio de san Marcos. La de Guipúzcoa, del colegio de Loyola, se cita en el extracto con su origen, pero el catálogo no la incluye. Si reconocemos este dato como digno de atención, es por que casualmente la cuantía de esa biblioteca, es la de mayor importancia entre todas las que informa, dato enriquecedor en nuestra valoración de esa trascendencia.

Extraña en esa uniformidad y pobreza informativa, algunas señales de cierto conocimiento: es destacable en la información tipográfica la puesta en valor de las ediciones maurinas, bolandistas, o las de ediciones de determinadas prensas antuerpianas, especialmente de clásicos. Sería valorable igualmente la apreciación de no encontrar en las bibliotecas sino libros antiguos, y pocos de ciencias modernas. Junto con estas aportaciones las referidas a la detallada descripción, cuando la hay, del editor y año puede deberse a un conocimiento bibliográfico o a la intención de poner de relieve el valor de un volumen, o de una obra. 
La orden unificaba el destino de lo incautado, por tanto, los comisionados recomendaban siempre, para los libros, el traslado a los Institutos de las propias poblaciones, y en los caso de obras de importancia, la Biblioteca Nacional.

La lectura del documento que relata la información de los comisionados nos informa de dos copistas para todos los resultados recogidos, con aleatoria dedicación en su cometido respecto a las calidades caligráficas y atención ortográfica.

En la descripción de los documentos de los archivos es constante la queja de no poder hacer el inventario por el desorden y abandono. Es constante igualmente un criterio que espiga las curiosidades - autógrafos de personajes famosos, instrumentos de culto histórico, como espadas o coronas, etc...-, de los valores archivísticos, aunque se citaban algunos de los numismáticos - monetario en Jerez-, o artísticos: se informaba de algunos cuadros - en Salamanca, Soria, Valladolid o León, en San Isidoro-, pero sin poner en ningún caso el nombre del autor de la obra, aduciendo "no haber persona perita en la localidad". En muchas ocasiones se explayaban en disquisiciones al margen, como son las quejas por el sueldo de los bibliotecarios o encargados del archivo, el porque de no encontrarse los índices del contenido de un archivo, por perdido, la descripción del mobiliario de las salas donde están los documentos, o incluso la exposición del pleito de un canónigo con sus superiores, en Santander, por no poder acceder desde tiempo atrás a los documentos del archivo. Excepciones en este pobre paisaje son los informes de los archivos de Huesca, la de los valores artísticos de San Isidoro de León, y parte de los de Tarragona. En los casos de objetos artísticos destinados al culto, se aconseja su permanencia en el centro donde ha sido reconocido, así mismo los documentos para el uso interno del ejercicio eclesiástico. La documentación archivística, con escasa excepciones, siempre se aconseja sea llevada al Archivo Histórico Nacional.

Hemos hecho anteriormente alusión al responsable de la memoria del archivo de la ciudad de Barcelona, d. Antonio Bofarull, a la que hasta ahora no hemos dedicado ningún comentario, en razón a la total excepción que supone su informe. El "riquísimo archivo de códices" de que se informaba en el extracto, está detallado por este experto de forma precisa, minuciosa, con el conocimiento de los instrumentos archivístico y bibliográficos necesarios para llevarlo a cabo, a los que se añaden comentarios personales de exquisita atención y sensibilidad. Enumera esta relación por una parte libros del archivo, cartularios o becerros, leccionarios o santorales, códices, misales anteriores a la imprenta, libros de coro, cabreos, constituciones, privilegios, o libros relativos a la administración de las rentas del cabildo, en el capítulo de los manuscritos; una riquísima exposición de la documentación diplomática del archivo, en su concepto la mayor riqueza del mismo; una lista de los libros contenidos 
en el archivo con detalle de edición y año, todo ello con su prudente y conocedora valoración de cada una de las entradas de la relación inventarial, constituyendo sin duda todo el informe una valiosa aportación en si misma y para la posterioridad de los fondos documentales de aquel archivo.

Incautaciones de bienes eclesiásticos

Hispania Sacra 57 (2005) 


\section{Primer Informe o Extracto del expediente general de la Incautación. ${ }^{9}$}

\section{Álava}

Es negativo el resultado de los bienes de la Catedral de Vitoria.

\section{Albacete}

Informaba su Gobernador de la inexistencia de bienes ${ }^{10}$

\section{Alicante}

Se reconocieron las localidades de Alicante, y en ella la Colegiata de san Nicolás y el Convento de Santa $\mathrm{Fe}$ (sic), y la de Orihuela, que dan las cantidades respectivas de 2440 libros, 250 en Alicante y 5000 de la sede episcopal. Se propone pasen a la Biblioteca Provincial y al Instituto ${ }^{11}$.

\section{Ávila}

De la iglesia catedral se informa de una biblioteca con 344 volúmenes impresos y 90 códices. De San Pedro de Alcántara algunos libros y objetos sin aparente valor. Se informaba que el archivo de la Catedral había sufrido la incautación de 1856. El resto y en ese momento bienes reconocidos del archivo catedralicio, se destinan al archivo histórico; los de san Pedro de Alcántara se dejan donde estaban, por ser desconocido su valor y costoso su traslado.

\section{Almería}

El escaso valor del archivo de la catedral desaconseja que se actúe con sus fondos.

\section{Badajoz}

No se reconocen valores de los que solicita el Decreto.

\section{Baleares}

El palacio episcopal de Palma contiene una biblioteca de 5322 volúmenes, de cierto mérito, que se destinan a la biblioteca provincial; se informaba conocer la existencia de libros en el archivo del cabildo de la catedral de la capital, aunque no fue posible reconocer su contenido "por no tener las llaves su administrador desde la incautación de 1855", En Alayor se deja donde está su biblioteca, de 84 obras, por ser de escaso

9 Sintetizamos y actualizamos el contenido del extracto para una mejor comprensión.

10 En informe aparte se ofrecía sin embargo una relación detallada de algunas incautaciones llevadas a cabo en conventos de la capital y provincia, aunque especifican que casi todos los legajos incautados están referidos a cuentas de sus propias administraciones. Esta información, la del coste ocasionado por los desplazamientos de los comisionados, por el traslado de los bienes incautados o por extras, fue la primera y constante en las sesiones celebradas en el Ministerio. Las proposiciones económicas acerca del mantenimiento de las nuevas bibliotecas, y su acceso público, ocupa igualmente gran parte de las resoluciones de la Comisión.

$11 \mathrm{M}^{\mathrm{a}} \mathrm{D}$. GARCÍA GÓMEZ, "Algunas informaciones acerca de las incautaciones de bienes documentales en la Provincia de Alicante en la desamortización de 1868". En prensa. 
mérito, e igualmente ocurre con el archivo de la catedral de Ciudadela. Se informaba que el del de Jornales se desconoce su antigüedad y mérito, posponiendo la decisión de sus fondos a ese conocimiento.

\section{Barcelona}

En la catedral se reconoce un archivo "riquísimo de códices" que se destinan al archivo histórico de Cataluña; en Vich se solicitaba formar un archivo, biblioteca y museo con los códices, libros y objetos artísticos del archivo y biblioteca del cabildo, adquiridos por el mismo con ocasión del la última exposición arqueológica; de Cardona informa de resultado negativo y de Manresa de la incautación de siete cuadros de su sacristía.

\section{Burgos}

Se recogía información acerca de ochenta volúmenes encuadernados, de plomos, que se remontaban hasta el s. X, del archivo capitular. En el Monasterio de Las Huelgas la abadesa había cedido dos códices y uno el rector del Seminario. Informaba la comisión que pedía datos sobre las bibliotecas de estas tres sedes, para poder informar con más precisión.

\section{Cádiz}

No se tuvo resultado alguno.

\section{Canarias}

Se informaba de mil trescientos tres volúmenes y ciento noventa y cinco cuadernos de la biblioteca del cabildo de la catedral de La Laguna, con propuesta de pasar a formar parte de la biblioteca provincial; en la biblioteca del cabildo de Gran Canaria se ignoraba el contenido, y se proponía igualmente su traslado a la biblioteca provincial.

\section{Castellón}

Informa la comisión de un resultado negativo, aunque se había hecho inventario de los cuadros que había en la catedral.

\section{Ceuta}

No se obtuvo ningún resultado de los informes de su Gobierno Eclesiástico.

\section{Ciudad Real}

Informaba de no haber en la provincia objetos de los requeridos por el decreto.

\section{Córdoba}

La biblioteca del la catedral tenía la cuantía de mil volúmenes. En el palacio episcopal se informa de doce mil volúmenes de algún valor, y se acuerda su agregación a la provincial, aunque un comentario acerca de la desaparición de algunos libros valiosos, hizo que se recomendara averiguar su paradero antes del traslado del total. Se informa que el archivo de la catedral estaba en completo desorden, sin índices, por lo que se pedía para su relación conseguir más detalles de su contenido. 


\section{Cuenca}

Se señalaba como importantísimo su archivo, con documentos relativos a la batalla de Lepanto, prinen por el Rey D. Pedro del obispo de Sigüenza. Del Monasterio de Uclés se refiere su excepcional biblioteca, de cuatro mil setecientos sesenta y cuatro volúmenes de gran valor. El archivo del Monasterio contiene los privilegios de la Orden. Por la singular importancia de sus fondos se aconseja que tanto los libros de esta biblioteca como los legajos de los dos archivos sean trasladados al Archivo Histórico Nacional y a la Biblioteca Nacional.

\section{Coruña}

Informaba de mil seiscientos volúmenes en la biblioteca de la Catedral de Santiago, propuestos para la biblioteca provincial.

\section{Gerona}

La biblioteca de la catedral tenía pocos libros, y por no tener índice se desconocía su contenido, aunque se informaba de dos códices, preciosos, que se acuerda destinar a la Biblioteca Nacional. El archivo de la catedral había sido incautado en la anterior desamortización; del archivo de la Colegiata de san Felipe, de las villas de Lladó, Villabeltrán, Ulla, y san Juan de las Abadesas de Besalú, se informa de sus anteriores incautaciones, en la de Lladó solo quedaba un legajo de pergaminos, y sellos en la de Villabeltrán. Se esperaba conseguir detalles de todas ellas para tomar los acuerdos pertinentes ${ }^{12}$.

\section{Granada}

Mientras que se informaba que tenía poca importancia el archivo de la iglesia catedral, en la capilla real se había encontrado un "precioso" misal manuscrito con la espada, el cetro y la corona de Fernando el Católico, junto con otros objetos encerrados en un armario con tres llaves, una de las cuales estaba en poder de la comisión de monumentos: se proponía el traslado del misal a la Biblioteca Nacional, y el resto de los objetos dejarlos en la ciudad, pues eran expuestos al público en ciertas celebraciones; en la catedral de Guadix se informaba haber mil ciento cuarenta y un volúmenes, que se proponían para la biblioteca provincial de Granada, en la parroquia de Baza no se refiere nada de importancia ${ }^{13}$.

\section{Guadalajara}

No se conocían en el momento de la relación los archivos de la vicaría de la magistral de santa María y de san Felipe; informan haber hallado mil quinientas veintisiete obras en la biblioteca de la colegiata de Pastrana, herencia de la biblioteca franciscana de aquella villa; los libros de la biblioteca del colegio de misioneros de esa villa se

12 No se menciona en este informe, ni en el segundo y más explícito, y solo se comenta en la sesión de 6 de abril de 1869, la existencia en la catedral de ...una Apocalipsis de san Juan comentada y una Biblia en vitela encuadernada en terciopelo carmesí, que deciden se trasladen al Ministerio de Fomento para su posterior entrega a la Biblioteca Nacional.

13 Acerca del misal manuscrito, ponderado con entusiasmo en ambos informes, no se dejó incluido en el ajuar de los Reyes Catolicos que guardaba la catedral, sino que se pidió su traslado a la Biblioteca Nacional. 
propone dejarlo como está por el uso de los mismos; de la catedral de Sigüenza la comisión propone llevar a Madrid la biblioteca, notable, sin decidir acuerdo acerca del destino de dieciséis cuadros de asuntos profanos.

\section{Guipúzcoa}

De esta provincia solo se informa de haber pedido detalles sobre el colegio de jesuitas de Loyola ${ }^{14}$.

\section{Jaen}

No de informaba del resultado de los bienes de la capital; de Úbeda, de la iglesia de san Salvador se inventariaron algunos cuadros que fueron reclamados como de su propiedad por el marqués de Camarasa, solicitud que fue atendida.

\section{Huelva}

Tuvo un resultado negativo en la pesquisa, en la capital y sus pueblos.

\section{Huesca}

Se informa de la importancia de los archivos de la catedral y de la iglesia de san Pedro. De la colegiata de Barbastro se decía había importantes libros de coro en la biblioteca, procedentes del monasterio de san Victoriano. La colegiata de Jaca tenía una biblioteca de mil setecientos treinta y seis volúmenes, que se recomendaba fueran llevados a Huesca, y en la colegiata de Tamarite se pedía fueran hechas las averiguaciones pertinentes pues se había encontrado los armarios del archivo vacíos, y esparcidos por el suelo cajones con papeles, que hacían suponer una diligente sustracción ${ }^{15}$.

\section{León ${ }^{16}$}

Se informaba de una biblioteca de mil seiscientos trece volúmenes de la Colegiata de San Isidoro, la mayor parte de los siglos XV y XVI, así como de cincuenta y nueve códices de inestimable valor, que se proponía fuesen trasladados a Madrid; igualmente tenía la colegiata gran número de alhajas, inventariadas como de gran valor artístico e histórico, de las que no se tomaba acuerdo sobre su destino. En la iglesia catedral se citaba un archivo riquísimo pero desordenado, y se precisaba informarse de datos. Los colegios de los Jesuitas tenían abundantes objetos e instrumentos de los gabinetes de

14 Acerca de la biblioteca de dicho Colegio, la intención de la Comisión era la de iniciar una búsqueda especial para localizar su situación, desaparecida en las pesquisas.

15 En sesión de 14 de mayo de 1869, el rector del Seminario reclamó la devolución del material científico, pero solo le fueron devueltos los objetos de Física y Geografía, faltando los de Historia Natural y Geometría, junto con enseres del Instituto. Por otra parte el Marqués de Ayerbe solicita la certificación de los documentos incautados en el Archivo de Tarazona, como reclamación del derecho de indemnización de diezmos, pues desde hacía tiempo el Marqués venía recibiendo la quinta parte de lo que en ese momento pretende. La Comisión acuerda que especifique la época de esa prebenda, y para ello se solicita al Secretario del Cabildo de Tarazona que lo certifique, hecho que no llega a poderse realizar por el sellado del Archivo de la Catedral.

16 La ciudad de León, por medio de su Gobernador, acordó solicitar la creación de un Archivo y Museo, anexo a la Biblioteca Provincial, que acogiera los ricos fondos de los Colegios de Jesuitas, contenidos en el monumental edificio de san Marcos. 
física, química e historia natural que se habían entregado al Instituto; la biblioteca de sus colegios constaba de cinco mil cuatrocientos quince volúmenes que se habían encontrado en cajones en una casa particular. Del hospital de san Marcos se dice que por haber quedado desocupado con la expulsión de los jesuitas, se proponía al gobierno reclamarlo como monumento artístico, con el objeto de conservarlo. Se informaba de abundantes objetos arqueológicos en poder de particulares en varias localidades de la provincia, de los que se había pedido presupuesto para su adquisición. En Villafranca una pequeña biblioteca era reclamada por su alcalde para quedársela el municipio.

\section{Lérida}

De su iglesia catedral, de Tremp, no se informaba de ningún valor. De la iglesia de santa María de Moya tenía las llaves el administrador desde 1843. En Balaguer el archivo era de escaso mérito, aunque había una biblioteca llamada "del obispo"de tres mil volúmenes; Informaba de algunas curiosidades el archivo de La Seo de Urgel.

\section{Logroño}

No tenía la capital para el informe nada reseñable, la parroquia de san Miguel y santa María del Burgo un archivo de escasa importancia.

\section{Lugo}

En la catedral de Mondoñedo se informaba de algunos objetos arqueológicos ${ }^{17}, \mathrm{y}$ se pedían informes de algunos códices desaparecidos. De la catedral se recomendaba el traslado a Madrid de ciertos legajos.

\section{Málaga}

No se pudieron conseguir informes de su archivo, que se recaban al Gobernador. La iglesia de santa María de Ronda tenía una biblioteca con el índice muy incompleto.

\section{Murcia}

No se informaba de la catedral por no haber bastantes datos, y se pedía el nombramiento de un nuevo comisionado que la aportara. En la iglesia de Cartagena se inventariaron objetos artísticos y arqueológicos, que se aconsejaba fueran trasladados al Museo Nacional; ${ }^{18}$ la falta de datos daba un resultado negativo en la iglesia de Lorca.

17 En sesión de 24 de abril de 1869 se reconocía la importancia delos objetos incautados en Mondoñedo, con noticia de los códices del s. XV que poseía la Iglesia y los libros y pergaminos que había requisado la suprimida Administracion de Propiedad y Derechos del Estado en 1857, 12 años antes, entregándolos entonces al difunto arcediano Troncoso y posteriormente al actual Penitenciario, en 1866.

18 El Alcalde de Cartagena remitió a Madrid las fotografías de ...la Lámpara y Cáliz procedentes del Oratorio de la Casa de Cuatro Santos... para que junto con los demás objetos de arte incautados a aquella Alcaldía fuera comprobada su llegada al Museo Arqueológico. 


\section{Navarra ${ }^{19}$}

Se informaba de una riquísima biblioteca en la catedral de Pamplona, de siete mil novecientos cincuenta y seis volúmenes, que la diputación provincial solicitaba para pública, la colegiata de Roncesvalles tenía igualmente una biblioteca de siete mil trescientos, de ricos documentos y códices que se pedía fueran trasladados al archivo y biblioteca nacional, pues se sabía la desaparición de documentos. Se remitía el índice del archivo de Tudela.

\section{Orense}

De la catedrales inventariaron nueve cuadros, sin especificar su valor.

\section{Oviedo}

No se informaba de la catedral y de decía desconocer los detalles de la iglesia de Covadonga.

\section{Palencia $^{20}$}

La iglesia catedral contenía un archivo y biblioteca de gran valor, pero no había presentado ningún informe, por lo que se reclamaba al gobernador; se informaba de veintisiete cuadros de la sala capitular, sin llegar a acuerdo sobre su destino. El resto de las pesquisas llevadas a cabo en Aguilar de Campoo, la abadía de Alabanza, la colegiata de Ampudia, habían tenido un resultado negativo, por falta de las personas ilustradas que colaborasen en el proyecto, que llevan a aconsejar que desde la capital se elabore el informe, ante el contenido en cualquiera de ellas de pergaminos de interés histórico.

\section{Tuy}

No se obtuvo ningún resultado de las averiguaciones.

\section{Salamanca}

Del archivo de la catedral, donde se informaba de documentos antiquísimos y tres buenos códices, se pedía pasase al Nacional, y en cuanto a la importante biblioteca de la catedral podía acomodarse en la Provincial. El convento de santo Domingo de la Espada de d. Juan de Austria debía pasar "a los museos de Madrid", del resto, de los conventos de las Dueñas, del de santa Clara o el de Carmelitas, asi como de Ciudad Rodrigo, no había informes suficientes. ${ }^{21}$

\section{Santander}

De la iglesia catedral, de su archivo y biblioteca, asi como de la catedral de Santillana se informaba no tener índices, y por lo tanto el resultado era negativo.

19 Se reclamaba en las sesión de 27 de abril de 1869 la búsqueda de una caja de marfil con inscripciones árabes que contenían las cenizas de Brunila y Alodia, procedentes de Fitero que estaban en ese momento en Sangüesa.

20 En sesión de 1 de mayo de 1869 se pedían noticias acerca de la biblioteca de la Casa de Jesuitas de Carrión.

21 Se acordó en sesión de 1 de mayo entregar el modelo de Tabernáculo de le catedral a la Comisión de Monumentos.

Incautaciones de bienes eclesiásticos

Hispania Sacra 57 (2005) 


\section{Segovia}

El archivo de la catedral se informaba que contenía, entre otros valores, legajos de música antigua, planos de la catedral, tapices flamencos, "libros curiosos", aunque no se había llegado a elaborar un índice por el desorden en que se encontraba. Se pide sean trasladados todos a Madrid. ${ }^{22}$

\section{Sevilla}

Se solicitaba al jefe de la biblioteca el informe de las bibliotecas colombinas, arzobispal, catedralicia, y del archivo. ${ }^{23}$

\section{Soria}

Desde la iglesia colegial de san Pedro se informaba de bienes de escaso mérito, solo se incautaron algunos cuadros de valor, haciendo mención de alhajas desaparecidas y se solicitaba información de algunos pueblos de la provincia, especialmente de Berlanga de Duéro.

\section{Tarragona}

El archivo de la catedral de Tarragona se había incendiado en 1811, aunque quedaban los restos de varios reyes de Aragón, procedentes del monasterio de Poblet, que se solicitaba fuesen trasladados al Museo Provincial. Los pergaminos del siglo XIII del archivo de la Comunidad de Beneficiados se informan para el Archivo Nacional, así como los archivos y biblioteca de la Catedral de Tortósa.

\section{Teruel}

Se informaba de no haber examinado los expedientes de Albarracín hasta no saber el resultado de la propuesta para la creación de un archivo histórico en Zaragoza, donde debían trasladarse todos los documentos importantes que se recogen de su jurisdicción.

\section{Toledo}

La biblioteca del Cabildo contenía novecientos volúmenes y su archivo los de las órdenes militares de Alcántara y Calatrava, de la de Santiago y la de la Santa Hermandad, documentos de la Inquisición, objetos arqueológicos y otros de historia natural: su informe lo daría una comisión especializada nombrada al efecto.

\section{Valencia}

Se daba noticia de un archivo importantísimo en la catedral, y de una biblioteca de seiscientos cuarenta y tres volúmenes de los cuales 197 eran manuscritos, que debían pasar a la biblioteca y archivo de la capital. La colegial de Játiva contenía sesenta y dos cuadros, el archivo de escaso mérito, a valorar por los comisionados los que debían pasar a la capital o quedarse en la ciudad. En la colegial de Gandía se inventarían cuarenta "magnificos" libros de coro del convento de san Jerónimo.

22 En sesión de 4 de mayo se acordó como medida excepcional realizar una reproducción fotográfica del cáliz del siglo XV que poseía la catedral.

23 No llegaron los informes a Madrid de estas tres importantes bibliotecas, como recogen ambos informes. 


\section{Valladolid}

En su archivo se informa de quinientos documentos y vitelas, infinidad de legajos y doscientos noventa y siete volúmenes manuscritos. La biblioteca contenía dos mil novecientos noventa y ocho volúmenes junto con ciento noventa y ocho en otra pieza, todos de importancia literaria. En el hospital de santa María de Esgueva había noventa y un impresos y setenta y ocho pergaminos, junto con los guantes y espada de d. Pedro Ansurez. De los conventos de santa Clara, Las Huelgas, dice el informe contener algunos pergaminos, el de Tordesillas una biblioteca de dos mil doscientos cincuenta y tres volúmenes $\mathrm{y}$ algunos pergaminos.

\section{Vizcaya}

Sin resultados en el informe.

\section{Zamora}

El archivo de la iglesia catedral no contenía sino algunos pergaminos, y se pide al comisionado que remita un índice. En la iglesia de la Horta se informa del archivo de la orden de san Juan, con multitud de privilegios reales y bulas, que se pedía su traslado a Madrid. De la colegiata de Toro, o de Benavente se ignoraba el contenido.

\section{Zaragoza}

Para contener los archivos de la iglesia del Pilar, el del Cabildo, o los de las catedrales de Huesca y Teruel se pedía la creación de un archivo histórico en la capital. En san Juan de los Panetes, el archivo de la orden de san Juan contenía doscientos documentos originales de los Reyes de Aragón, trescientas veintidós bulas, trece cartularios en vitela, cuarenta cartas pueblas, etc... El archivo de la iglesia de santa María de Calatayud contenía igualmente gran número de privilegios y bulas, así como los de la orden del santo Sepulcro, con doscientos legajos e impresos; la parroquia de santa Engracia libros de coro y tapices antiguos. Todos los informes de esos valores junto con los de los archivos de Daroca, Tarazona, Caspe, Borja, Cariñena y Sos, debían remitirlos los comisionados. 
Segundo Informe o Catálogo de los Papeles libros y objetos de arte incautados al clero en virtud del Decreto de 1 de enero de 1869.

\section{Alicante}

Biblioteca Episcopal de Orihuela. Consta de 4860 vols. correspondientes a 1190 obras, de las cuales 1187 están impresas y tres manuscritas. Tratan de Teología 424, de Historia 706, de Bellas Artes y Literatura 189, de Jurisprudencia 186, de Ciencias 74, Enciclopedias y Revistas. Están escritas en castellano 510, en latín 632, en francés 9 ,en italiano 5 , en valenciano1, en lenguas muertas 3 , en varias lenguas.

En la Iglesia colegial de Alicante se ha encontrado una biblioteca de 2400 vols. de obras modernas y en el convento de santa Faz otras 250 o 300 cuyo contenido no se conoce todavía.

Comisionado por Orihuela d. Román García Aguado, por Alicante d. Antonio Galtero.

Destino que se propone. La Biblioteca episcopal de Orihuela pasará a la Provincial de Santo Domingo, y la de la Colegiata y Santa Faz a la del Instituto.

\section{Ávila}

Biblioteca de la Catedral consta de dos secciones, la de impresos y la de manuscritos; la primera la forman 344 vols. que tratan la mayor parte de derecho canónico y civil, Sagrada Escritura y Santos Padres. Esta sección será la que por la elección de las obras, se recomienda por los caracteres tipográficos que las distinguen, perteneciendo en su mayor número al primer siglo de la imprenta y mereciendo entre ellas especial mención como preciosidad bibliográfica el famoso Catholicon de Juan de Jauna, impreso en Maguncia en 1460, sobre vitela, y atribuido con fundamento a las prensas de Gutemberg, además de otras obras sin fecha ni lugar de impresión, que podrá verse en el inventario $\mathrm{n}^{\circ} 2$. La sección de códices consta de 90 volúmenes que tratan en su mayor parte de derecho canónico y civil. La verdadera joya de esta sección es una Biblia del siglo XII con preciosas iluminaciones del gusto bizantino y otras varias obras perfectamente escritas e iluminadas, vease el apéndice $\mathrm{n}^{\circ} 3$. Tanto los impresos como los códices fueron trasladados a Madrid por Decreto del 2 de feb. de 1869 y se hayan depositados en el Archivo Histórico Nacional, para ser trasladados algunos de ellos a las bibliotecas Nacional y de San Isidro.

Archivo de la catedral: Las llaves de esta dependencia se hallaban en poder de la Hacienda Publica desde el año 1816. En la imposibilidad de formar un inventario de sus papeles y documentos, por el completo desorden en que se encuentran, se agruparon en seis legajos, los Privilegios Reales, Bulas y Documentos históricos, formando otros varios hasta el número de 71 en los que bajo el nombre de diezmos, censos y ejecutorias se contienen muchos papeles dignos de ser conservados, pudiendo citarse entre ellos algunos autógrafos curiosos, de Fr. Felix Lope de Vega Carpio. Vease el apéndice $\mathrm{n}^{\circ} 4$. Estos 71 legajos se han trasladado al Archivo Nacional , entregándose al Cabildo las llaves de su archivo con todos los papeles referentes al gobierno de su iglesia y parroquias de la capital. Se han reconocido también todos los archivos de las 
parroquias cuyas llaves se hallaban también igualmente en poder de la Hacienda Pública y está acordada la traslación de sus papeles a este archivo histórico.

San Pedro de Alcántara, en la villa de Arenas; en este santuario se han encontrado algunos cuadros cuyo mérito no ha podido apreciarse por falta de personas peritas en la localidad, y varios libros comunes y de poco valor. La Comisión ha tenido en cuenta la dificultad de trasladar estos objetos por la posición topográfica que ocupa aquella iglesia, y propuso en su día que los objetos incautados se entreguen bajo inventario al encargado de misma quien será en todo tiempo responsable de su custodia.

\section{Baleares}

Biblioteca Episcopal de Palma: Fundó esta biblioteca con carácter de pública a tenor de lo dispuesto en Real Cédula de Carlos III de 17 de Febrero de 1771 (Ley 5a, Título XIII, Libro II de la Novísima Recopilación) el último Obispo de esta diócesis, Juan Diaz de la Guerra aumentándose poco después con los libros que pertenecieron a los expulsos P.P. Jesuitas del Colegio de, la villa de Pollensa, y en el año de 1798 el Cabildo de la Santa Iglesia Catedral resolvió pasar a ella los restos de la que él poseía, que antiguamente parece no carecía de importancia, si bien en aquella época había ya perdido gran parte de la misma.

Resulta contener los siguientes.

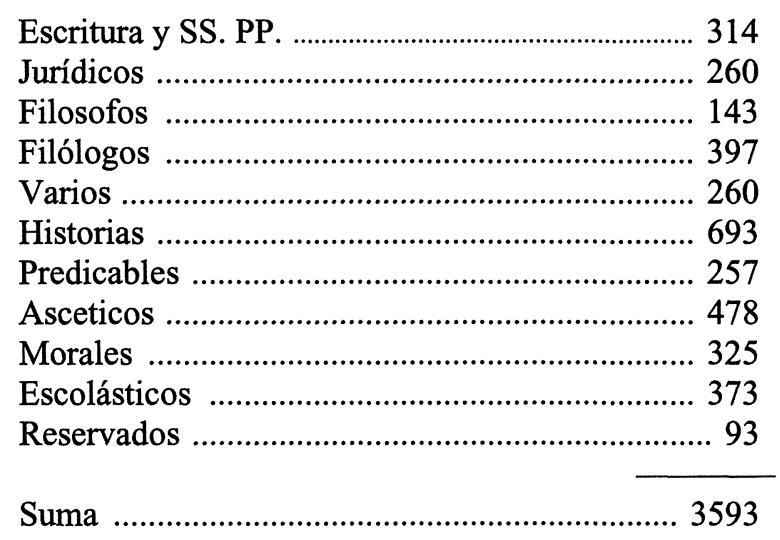

Tocante al mérito intrínseco de las obras pocas son de una importancia relevante, si se exceptua la Biblia Poliglota del Cardenal Jiménez de Cisneros, las ediciones Maurinas de los Santos Padres, el Virgilio ad usum Delphinis, las Medullas antiguas de España del Padre Florez y otros varios y unos treinta y cinco incunables que he podido contar recorriendo el índice, de los cuales solo llaman la atención Apuleius, Opera, Roma 1469, Séneca Opera Omnia Napoli 1475, Lullius Arbor Scientia Barcinona 1482, Lexicon Greco Latino Vincenticce 1483. Entre los escasos manuscritos parece que no hay mas que un Salustio que sea verdaderamente notable.

Comisionado d, Bartolomé Muntaner. Esta Biblioteca pasará a formar parte de la Provincial.

Incautaciones de bienes eclesiásticos

Hispania Sacra 57 (2005) 


\section{Barcelona}

Según consta sobre la memoria histórica descriptiva sobre el archivo de la Catedral de Barcelona escrita por d. Antonio de Bofarull. Contiene entre otras cosas 21 códices en vitela en las siguientes clases: cuatro grande cartularios en folio mayor bajo el título de Antigüedades de la Catedral en letra grande de los siglos XIV y XV. El título de estos libros es impropio por lo basto y no ha de recordar a V. E. El objeto de un cartulario o becerro para declarar que lo que en ellos se encierra son copias de todas las antiguos documentos desde la época mas remota que conserva el archivo, esto es, el contenido de los documentos guardados en las tres salas reunidos en tomos para su conjunto más manejable, sin que el investigador tenga que perder el tiempo desenrollando y rollando pergaminos. De utilidad tan inmediata eran estos volúmenes y tal la confianza que merecía su contenido que según advirtió su antiguo Sr. archivero, de ellos se obtenían directamente las copias testimoniadas, como si se procediera de un manual de escribano, de manera que así llegaría a prescindirse de su comprobación con el original guardado en su respectiva área, lo que sí puede producir fe histórica, no así tanto judicial, por no proceder de un registro o una minuta autorizada.

- Ocho magníficos volúmenes, tal vez verdaderos códices, seis de ellos en gran folio, comprendiendo leccionarios y santorales de diversos meses y familias para ciertas solemnidades. La letra es parecida a la de los cartularios y no se distingue por ilustraciones de ningún género.

- Dos códices en vitela con letra del siglo XV, comprendiendo el uno las Solemnidades de la Virgen y del Corpus, y el otro antiguas Constituciones de Capitulos Generales: éste de notable belleza en la parte material.

- Un Misal anterior a la imprenta en delicada vitela y letra probablemente de últimos del s. XIV, con iniciales de preciosas flores y otras letras iluminadas. Le faltan a este libro cincuenta folios y esta sería la causa tal vez, porque considerándole como inservible, lo arrojaría alguna mano profana en lo alto de un armario, dejándole a merced del polvo que le sirve de cubierta y con todo y en abandono y la parte que le falta, en la que se comprendería la lámina de la portada, anticuario habría que lo colocara en un lugar preferente en un lugar de su biblioteca como merece un resto que tantas bellezas completas obstenta en cada una de sus iniciales.

- Tres libros, el uno de coro y los dos de uso menos constante, pues sin ser de coro servían de guía para el canto de algunas ceremonias especiales, no frecuentes, como se comprenderá por sus títulos que son: Misa de Difuntos, Misa de la bendición de la Abadesa, Misa de Consagración de Obispo Elector. El último tiene algún deterioro que no ofende la parte escrita, pero los tres están en buen estado de conservación, forma en escritura grande, caracteres del s. XV; es limpia y flexible su vitela y en ella destacan mayúsculas floreadas y otros adornos de gran mérito.

- A estos tres pudieran agregarse por ser de la misma clase un gran libro, cuya cubierta mide cuatro palmos cuadrados, escrito también en pergamino y con grandes caracteres, distinguiéndose sus inmensas iniciales por los bellos adornos que las forman, comprendiendo el rezo de la Concepción, antes exclusivo de los frailes menores y extendido en el siglo último al clero secular y regular, según se expresa en la porta- 
da: Aunque los caracteres son antiguos, incluidas las iniciales, juzgo que es muy posterior al siglo $\mathrm{XV}$, pudiendo considerarlo como una bella imitación de algún otro libro anterior del mismo género, o valiéndose de moldes o planchas antiguas para el dibujo y pintura de las letras, de manera que puede distinguirse lo imitado de lo añadido por el copista, que no sería tampoco el que confeccionó la portada, según se comprende por la referencia que en la misma se hace al cambio de rezo en el siglo anterior. Sus cubiertas son de madera, con grandes chapas y clavos de latón.

- Otros cinco libros se encuentran también esparcidos en diversos estantes, escritos en pergamino y con antiguos caracteres, y estos pertenecen, como antes he indicado, a la antigua administración de las rentas del Cabildo o de la Seo. Consiste el primero en un curioso Cabreo que comprende Confesiones de_Derecho desde 1419, otro en simples apuntaciones de aniversarios, otro en actas de prestaciones de censos pertenecientes a aniversarios comunes, otro en claúsulas de testamentos sobre iguales fundaciones, y otro, por fin, que reúne en sus páginas constituciones, privilegios y donaciones del Monasterio de Estany. El mas notable de estos cinco códices o libros es el segundo por su letra monacal y por las mayúsculas iluminadas que lo adornan. El último que se encuentra en un armario muy bien ordenado que constituye el archivo especial de las cinco Dignidades Reales, ya extinguidas, es notable bajo el punto de vista histórico por referirse su contenido a un Monasterio de grande antigüedad. Como complemento de esta parte, pueden citarse también mereciendo ser agregados a la misma, un cuaderno suelto que parece haber formado parte de su antiguo cartulario, un libro en pergamino que trata de obligaciones de los pabordes, letra del siglo V, y otro en pergamino y papel a la vez que lleva el título de Tabla de los beneficios de la Seo de las Iglesias de la ciudad y del Obispado.

Los códices en papel no pasan de diez y de ellos pudiera decirse lo que se ha dicho ya de los escritos en vitelas, tanto por lo que toca a su parte textual o esencial como a lo material. Los mas importantes por su contenido son tres, como puede comprenderse por sus títulos, a saber: un tratado del Privilegio de la moneda de terno otorgada por el Rey D. Jaime I a Barcelona. Derechos que cobraba en el siglo XV la Condesa de Gérica y Registro de Tesorería del Rey D. Pedro IV. Este merece especial recomendación tanto por revelarse en él el sistema de Contabilidad del Tesorero Olsinellas, tan conocido en la historia, como por lo bien conservada y caprichosa encuadernación que la salva, sin duda alguna la primera que tuvo, consistente en pergamino sin lustres y blanqueada, con diversas molduras de relieve. Los demás libros de esta clase , algunos del siglo XV y otros mas antiguos comprenden: Privilegios de los Sumos Pontifices, legados y otros Obispos.- Constituciones de la Iglesia de Barcelona. - Oficios Mayores de la Seo.-Constituciones Provinciales de Zaragoza.- Instituciones de limosnas en el refectorio de la Pía Almoyna y Censos del mismo establecimiento.

A los Códices de esta clase pueden agregarse aunque de un siglo posterior, del XVI, un Espéculo de las porciones que la Pía Almoayna da a los pobres en el refectorio de la misma, y de algunos derechos que cobra en diversas partes.

Aunque de utilidad desaparecida el contenido de este libro lo recomienda una grande especialidad, cual es el haberse escrito bajo la dirección de Tarafa, el archivero más celoso que ha tenido el Cabildo y que más se esmeraba en el orden del archivo y 
en el buen gusto de los libros que habían de guiarle para el fácil encuentro de los demas que guardaba, según he tenido ocasión de observarlo; adornan por otra parte este libro varias portadas hechas a la pluma conteniendo los escudos de armas de los mayordomos o administradores dela Pía Almoayna y lo mas notable de la arquitectura que allí se ostenta es la verdadera del Renacimiento boyante en la época en que se hizo el libro (1506) vistiendo las figuras que hay en los extremos los trajes mas propios de aquella. Aun mas resalta entre sus páginas una curiosa lámina hecha también a la pluma, representando el refectorio de la casa de Almoayna en el acto de comer los pobres, y por su mérito, sin exageración, me atrevo a asegurar que produce en el ánimo del que lo contempla un efecto algo parecido al que se experimenta ante los cuadros de género de la escuela Flamenca y Alemana, confirman la opinión que he manifestado respecto al archivero Tarafa otros tres volúmenes de inventarios de escrituras del mismo establecimiento de la Pía Almoayna, hecha por el mismo estilo que el que acabo de describir, con iguales cabeceras de grandes letras góticas, aunque no con las especiales circunstancias que distinguen el libro del refectorio, todos escritos también bajo la dirección de aquel celoso al par que erudito archivero.

Los demas libros manuscritos que nada tienen de codice en su aspecto ni por la letra en que van escritos, pues son posteriores al siglo XV, pero que merecen ser exceptuados por su importancia histórica, o mas bien por el servicio que pueden prestar a la historia son los siguientes:

- Nueve volúmenes, incluso el índice de los impresos, comprendiendo los interesantes trabajos del sabio Caresmar, uno de los primeros hombres de este siglo, que , dotado de verdadero espíritu histórico y con delicada critica, prestó mayores servicios a la historia patria, sobre todo a la eclesiástica y de cuyo mérito no hago aquí alabanza cuando lo han hecho ya plumas tan bien templadas como las que manejan los Flores, Merinos, Canales, Finestres y Villanuevas.

- El manuscrito original del Epicopologio de Barcelona, por Francisco Tarafa,del que hablaban Doménech, Aymerich, los autores de la España Sagrada y cuantos han intentado regularizar la serie histórica de los prelados de esta diócesis.

- Cinco volúmenes, truncados, de ejemplares de cosas memorables para guía de la iglesia.

- Tres volúmenes de Ejemplares de la Sacristía, sumamente curiosos, por explicarse en ellos los oficios que se celebran, por ser a la vez su dietario de hechos históricos y notables.

- Dos volúmenes, el primero con el título de Origen y Fundación de la insigne Orden del Toisón de Oro, Capitulos y nombramiento de sus ilustres individuos, desde su institución hasta el año de 1756, y el segundo con el de Institución de la Sagrada Orden del Toisón de Oro, asambleas y nombre de sus insignes individuos, desde el origen en el año 1429 hasta el del año de 1587, ambos notables, pero especialmente el último, por alternar con el texto varios dibujos de pluma imitando las inscripciones emblemas, y escudos de armas que se conservan en las sillas del coro de esta catedral, donde se celebró el primer capítulo, si bien es de notar que algunos dibujos no están 
concluidos, y otros quedan por hacer, sin mas imitación que la letra alemana de su pie indicando el personaje.

- Un tomo miscelaneas impresas y manuscritas con varios sucesos dela guerra de sucesión.

- Un dietario del siglo XVI, relativo a sucesos de la Catedral.

- La vida del Canónigo Pedro Font, escrita por Jaime Ramón Vila: año 1614, libro que no dejaría de ser útil en lo que toca a la parte de biografías españolas si se tiene en cuenta la importancia que el autor le atribuye a la que da a este D. Nicolas Antonio, llamándole varón noble y muy diligente y versado en la Historia.

- Un volumen que contiene los Informes de la vida del santo Arzobispo Blazquez $y$ de su culto inmemorial.

- Y finalmente otros tantos manuscritos de interés mas secundario, aunque útiles, como se comprende por sus títulos, que apuntamos aquí por mera curiosidad: Del hospedaje que se daba a los enfermos, peregrinos, estudiantes, nobles y huerfanos en el hospital de Olisa (¿ u Oleia,) -Capitulares de su Monasterio de monjas, -Erección del Seminario Episcopal, -Visita en la Catedral por un Obispo de Barbastro, etc...

- Aparte de los códices existe en el Archivo de la Catedral otra clase de papeles, que mas o menos directamente puede ser considerada como auxiliar de la historia, pues de ellos se deducen antiguas costumbres y se sacan consecuencias en cuestiones de jurisdicción eclesiástica, que pueden ser tomados como datos fehacientes para ulteriores dudas que en esta parte se ofrezcan. Se da cuenta de ellos en el Inventario bajo el nombre general de procesos, comprendiendo asi los criminales como los civiles. Entre los primeros sobresale uno de heregía, contra varios individuos en 1340, el que bien examinado quizás facilitaría datos para probar a la existencia que dejaron en Cataluña, en el siglo XIV los Albigenses o Valdenses, que tanto figuraron en el anterior, o para acreditar los preludios del sistema que mas adelante había de servir de base para la erección de un Tribunal, odiable para cuantas personas se precian de ilustradas y sepan apreciar la caridad evangélica. Entre los segundos se encuentran los que tratan de los siguientes asuntos o cuestiones:

- Entre el Obispo Dimas de Lioris y el cabildo sobre la jurisdicción mixta entre el Cabildo y los siete parrocos de Barcelona.- Entre el Cabildo y la Parroquia de Santa María del Mar.- Entre el arcediano Rivera y el Cabildo.- Entre el Prepósito Ferrer y la Almoayna.- Entre los nobles laicos de Cataluña y el arrendador del excusado.Como precedente o corolario de estos mismos procesos y de otros que no existen, puede añadirse a esta colección especial otros memoriales, miscelaneas, cartas y apuntes que se encuentran relativos a los encargos de los comisionados que el Cabildo, el Obispo y demas interesados respectivamente enviaron a Roma, algunas veces en aclaración de los derechos disputados o para realizar ciertas pretensiones, tales como por ejemplo si los obispos debían percibir las distribuciones en ausencias y enfermedades, si el Cabildo debía conservar el Patronato de las Rectorías, si debía aquel sujetarse al fiscal de la curia eclesiástica, y otras por igual estilo. No pueden omitirse entre las mismas clases de procesos, otras de asuntos menos serios, pero que no dejan de ayudar al conocimiento de ciertas costumbres, tales como uno entre el Cabildo y un particular

Incautaciones de bienes eclesiásticos

Hispania Sacra 57 (2005) 
en el siglo XVI, donde incidentalmente se pretende probar la entrada de los nueve barones de la Jaina en Cataluña, el que medió entre la municipalidad y el Cabildo por efecto de la prohibición que hizo aquella de que se comprase pan fuera de los hornos de la ciudad, y de protestar el Cabildo por esta prohibición, tocase al horno de la Canónica era contra la libertad eclesiástica; el instruido contra el Vicario perpetuo de San Justo y Pastor por haber tocado la campana antes que la Catedral en 1708, y finalmente el relativo a la distribución y emolumentos del canon que pretende D.Dalmau de Copons durante su ausencia del Principado en la Guerra de Sucesión.

Para completar esta parte de los libros escritos que pueden ayudar a la historia, se pueden incluir los cuatro últimos que quedan en mi lista de aportaciones, de un carácter sumamente particular, y que de ningún modo confundiría yo con los demas de Administración y cuentas, por más que pertenezcan a esta clase: sus títulos descubrirán a V.E. la razón por la que los exceptuo: Libro de entradas y salidas del batallón.empezando en 1648; -Libro de cuentas del batallón; - Libro de gastos de la Compañía armada por el Cabildo para socorro de Gerona en 1657; dos tomos.

Si son los libros o Códices, E. S. uno de los elementos mas favorables a la historia, no lo es menos, y en este particular archivo me atrevería a asegurar que es superior, el conjunto diplomático que encierra, y que en mi concepto constituye su principal riqueza. Como puede comprobarse en el Inventario la suma total de rollos de pergamino que yacen en sus estantes asciende al número de 6762; pero como bajo el nombre de rollo he contado asi el pergamino como el conjunto de dos, cinco, diez, quince o mas que se encuentran envueltos juntos presentando un solo tubo o legajo (para cuya entretenida separación es preciso que el polvo no lo dominase y que fuese menos perentorio el cumplimiento de su encargo) calculando con prudencia que aquella suma puede añadirse por dicha razón, cuanto menos otra quinta parte de la misma, su resultado sera presentar una riqueza diplomática compuesta de 8112 pergaminos de todos los siglos y de diversos caracteres. No es solo la utilidad paleográfica lo que estos escritos ofrece, tanto que por ellos puede tratarse un curso completo de estos estudios, sino la de otras mil soluciones que asi interesan a la historia en particular, como a los derechos individuales. Por ellos puede comprenderse la duración de la cuenta por años de los Reyes de Francia, y puestas a veces, el partido que siquiera la Cataluña primitiva en las dobles aclamaciones a una época de intrusos reconocidos en diversos extremos; por ellos puede reconocerse los primeros asomos de nuestra lengua catalana escrita y la mayor cultura tocante al latín; de los cancilleres y escribanos de los siglos XIII, XIV y XV comparados con los levitas y notarios rústicos de los primeros siglos de la reconquista; los cambios de apellidos y nombres geográficos; las circunspecciones y redalías de varios señoríos y antiguas propiedades, sucesión genealógica y de dominio de algunas familias, los lindes de muchas casas y haciendas ( por cuya ignorancia se han suscitado tantos pleitos) los nombres de varios artistas que han construido monumentos celebres como la misma Catedral y la exactitud de varias indicciones y años de pontificado; en ellas se pueden estudiar antiguas y curiosas formulas e investigar utilísimos datos de desaparecidas costumbres, y sobre todo en lo que toca a la parte de testamentos, de que hay un inmenso armario atestado, cuantos particulares habrán encontrado allí una suspirada joya en busca de la cual gastaron en vano y en vano re- 
gistraron los depósitos y las librerías de todos los notarios. Después que esta gran colección de pergaminos estuviese debidamente ordenada y clasificada, reducidos a alfabeto los nombres a que hace referencia y extractados su contenidos con las observaciones convenientes sobre la parte histórica, royados con sus argoyas números y cartelas exteriores, limpios, ventilados y presentando a la vez y en conjunto su número y variedad, de seguro que dejaría admiradas a los que antes no lo conocieran, y mirándola como un rico tesoro, como tal se gloriaran de poseerla a par que otros envidiaran su posesión. Cuando llegue este caso no dudo que este tesoro ostentará todavía mayor brillo a medida que vayan apareciendo antiguos e interesantes diplomas, que allí a la fuerza han de existir, y que no he tenido la suerte de encontrar ahora con la inspección solamente superficial que de todos hice, como son, entre los llamados Reales, algunos preceptos de los Reyes francos desde Ludovico Pío, de cuya época data la restauración ya jamas interrumpida de esta Iglesia. Aunque esta esperanza la acompañe yo con un lamento, por no haber tenido la dicha de cumplir en esta ocasión, puedo gloriarme, con todo, de haber podido contemplar con mis propios ojos, uno de los documentos mas raros de nuestra historia, ya mentado, y glosado por varios criticos, tan raro que quizás es el único existente en sú clase en toda España: tal es el convenio establecido entre el Wali o Rey Mugheid, junto con su hijo Alí, de las Baleares, y el Obispo Guilaberto de Barcelona, en 1085, en virtud del cual promete aquel, que si llega a conquistar del puro católico que allí se establezca dependiente del de Barcelona, de manera que viene a ser de este modo el wali árabe e islamista provisor de una sede episcopal cristiana y en terreno dominado por los partidarios de aquella secta. El estado de conservación de este documento es magnífico, habiendo notado que al pie del mismo hay tres lineas en árabe, que comprenden todo lo ancho del pergamino, de los que no se da cuenta en la copia que de su contenido publicó algún autor.

No siendo notable ni numerosa la colección de libros que se encuentran esparcidos en diversos puntos de este archivo, aunque reunidos en la primera relación, damos aqui noticia formando una lista esacta de los títulos y de sus respectivas ediciones: tomos.

- Constituciones Pontificias, por Luis Guerra, edición de Venecia, 1772, cuatro

- Breviario Gótico Mozarabe, según la regla de San Isidoro, ed. de Madrid, Ibarra, 1775.

- Obras de San Paciano, obispo de Barcelona, traducidos por D. Vicente Naguera, ed. de Valencia, Monfort, 1780.

- La Sagrada Biblia, traducida por Torres Amat, nueve volúmenes.

- El tomo V de la Crónica de Cataluña, por Pujades.

- Exequias por la Universidad de Cervera a su fundador el Rey D. Felipe V ${ }^{o}$, Imprenta de la Universidad, 1746.

- Festejos de la Universidad de Cervera cuando la proclamación de Fernando $6^{\circ}$.

- Real Patronato de la Merced, por Rivera, edición de Barcelona, Campins, 1725.

- Centurias $1^{a}$ de la Merced, por id. id. en 1726.

Incautaciones de bienes eclesiásticos

Hispania Sacra 57 (2005) 
- Defensa de la primacía de Toledo, por Sevillano, edición de Madrid, Imprenta Real, 1725.

- Obras de Esteban Borgia, en tres volúmenes, comprendiendo la Cruz Veliterna, La Cruz Vaticana y la Cofesión Vaticana, edición de Roma, imprenta de la Congregación de Propaganda Fide, 1780, 1779, 1776.

- Memorias Históricas de Barcelona, con el Libro del Consulado por Capman, ed. de Barcelona, cinco tomos.

- Memorias del Cabildo de Sevilla sobre la Primacía de España, sin imprenta ni año.

- Plan del Canal de Urgel, a solicitud de la Junta de Comercio, ed.de Barcelona de 1816.

- Misal en letra gótica o de torlis, impreso en Lion, por Bernardo Lescuyer, a expensas de los libreros de Barcelona en Abril de 1521.

- Otro igual al anterior. 1622.

- Pontifical Romano de Clemente VIII, ed. de Antuerpia, oficina Plantiniana

— Misal del siglo anterior, ed. de Antuerpia, oficina Plantiniana.

- Id. mas moderno.

— Id impreso en 1633.

- Ritual de la Iglesia de Barcelona, de Barcelona y Ferrer, 1743.

- Pontifical_en dos tomos impreso en Roma, de Rubis, 1661.

- Id imprenta Vaticana, 1726.

- Id truncado.

- Canon de la Misa para uso de obispos y prelados, id. de Roma, Salvioni, 1748.

- Pontifical de la Semana Mayor, ed. de Orbina, imprenta del sacramento, 1727.

— Epístolas, ed. de Madrid, imprenta de la Cruzada, 1675.

— Id. id id. García, 1731.

- Canon de la Misa para uso de los Obispos. Anissi, 1680.

- Vida de los obispos de Barcelona, por Tarafa.

- Prescindiendo del mérito delos textos y del buen nombre de los autores, lo más recomendable de las ediciones citadas es la de las obras de Esteban Borgia, impresas en Roma en el último tercio del siglo pasado y la traducción de las obras de san Paciano, contemporaneo en impresión de aquella, y salida de un establecimiento español, no menos célebre que el romano de propaganda fide, cual es el de Monfort de Valencia. Pero como edición antigua entre los pocos ejemplares modernos que posee el archivo de la catedral de Barcelona, juzgo que no habrá pasado desapercivido a los ojos de V.E. pues son notables por su antiguedad y por el lugar donde se imprimieron, los dos misales de letra gótica, dado a luz en Lion en 1521. Estos dos libros cuya edición es tan rara como vella, compañeros en polvo y abandono del celebre misal manuscrito en vitela de que antes he hablado, pues yacen asi mismo arrojados quiza de siglos encima 
de la estanteria donde aquel se encuentra, merecían en mi concepto ser guardados hasta en un lugar preferente no solo por su testimonio de los primeros misales impresos que uso la iglesia, sino por acreditar su portada el espiritu comercial de esta ciudad, cuyos libreros, no contentos con las impresiones propias, costeaban para su despacho, las que mejor pudieran hacerse en el extrangero, aun cuando debiesen prestar homenaje a un habil propaganda del arte de Gutemberg, como realmente seria Bernardo Lescuyer. Es mas especial y recomendable este hallazgo cuando por esta circunstancia puede decirse que ni la privatiba de-los monges del Escorial dada por Felipe II para la impresión de los libros del rezado, ni la facultad exclusiva de la Cruzada, a igual objeto existían todavía.

Este Archivo pasará al General de Cataluña exceptuando los libros impresos que se pasaran a la Biblioteca Provincial, y los papeles pertenecientes al gobierno interior de aquella iglesia y de escaso valor histórico que se devolverán al cabildo.

El Archivo de la Catedral de Vich segun la memoria escrita por el comisionado d. Mariano Aguiló consta de

\section{Burgos}

En la catedral no hay de importante mas que una parte del Archivo donde se conservan, encuadernados, en unos ochenta volúmenes, diplomas que remontan hasta el siglo.

Se han recogido tres códices escritos en pergamino y encuadernación en tabla, muy deteriorados, pues carecen de varias hojas, y en los que quedan muy mutilados, por haberlos cortado, viñetas y letras capitales, dos los cedieron la Abadesa y comunidad de las Huelgas y otro el Rector del Seminario.

Tanto estos códices como los ochenta volúmenes de diplomas se trasladarán al Archivo Histórico Nacional.

\section{Cáceres}

El resultado de la incautación en esta provincia ha sido escaso, pues solo en el Archivo de la Catedral de Coria había algunos documentos importantes que desaparecieron en parte en épocas anteriores, pues no constan en el índice que se formo en 1858.

\section{Cádiz}

Jerez de la Frontera, según la memoria escrita por d. Manuel Bertematí la biblioteca colegial de esta ciudad consta de 4329 volúmenes, de los cuales forzoso es separar antes del verano unos 100 volúmenes completamente comidos por la polilla y hasta 800 mas que aunque atacados del gusano pueden salvarse en parte si se aplica pronto remedio. No existe formal indice de esta biblioteca, pero los Sres. Canónigos tenían para su uso una lista alfabética, que han puesto cortesmente a disposición del infraescrito comisionado, con cuyo auxilio se ve facilmente que hay multitud de obras incompletas sin que pueda el informante fijar hoy con seguridad esta lamentable falta, por el corto tiempo que se le señala para un trabajo de esta índole, que es de suyo largo y fatigoso. Es de advertir, además, que en la suma de volúmenes arriba expuesta, entran algunas decenas de folletos, opusculos y otros impresos, todos de modernas fe- 
chas y casi todos de escaso o ningún interés, de manera que a juzgar por este primero y rapido examen, las obras verdaderamente útiles no llegarán a 3000 volumenes, salvo rectificación y contando siempre con el inmediato remedio de los datos arriba indicados. Bajo el punto de vista bibliográfico no está la biblioteca al nivel de los conocimientos modernos, pero es un verdadero muestrario de la erudicion clasica atesorada hasta mediados de pasado siglo. Dominan en ella las Historias propiamente dichas, y las Letras Sagradas, contando en esta parte algunas Biblias Políglotas, codices, vitilas y M. S.S. hebreos, griegos y latinos, de gran interés para el anticuario pero cuyo estado de conservación deja mucho que desear. Los documentos que por su indice pertenecen al Archivo, aunque se hayan incorporados en las estanterias, son en su mayor parte relativos a suntos eclesiásticos: entre ellos podrán tener interes algunos referentes a Raimundo Lulli, y formando excepcion un Indice de las escrituras publicas otorgadas en Jerez desde remotos tiempos hasta el último tercio del pasado siglo, cuya natural colocación es el Archivo local del Notariado: El monetario parece recompuesto y rellenado en epoca reciente: consta de 1577 ejemplares de cobre, 529 de plata y 31 de oro, repartidos sin orden en 60 tablas y otros sueltos en un cajon. El erudito Pons hace mención en sus Viajes de esta coleccion de medallas y monedas y sin duda sería en aquella epoca signo de tal recuerdo: pero en el dia ni por el valor material ni por el numismático merece mucho aprecio, salvo mejor criterio pues se componen casi en su totalidad de monedas romanas vulgares. Por ultimo los estantes que son de caoba antigua, sin puerta, cristales ni alambrados, necesitan limpieza y reforma, pero sin moverlos del muro a que estan sugetos, so pena de destrozarlos inutilmente.

Esta biblioteca y monetario quedaran en la localidad, abriéndose al servicio público a costa del municipio de la misma que ha ofrecido consignar en sus presupuestos la cantidad necesaria para este objeto ${ }^{24}$.

\section{Canarias}

La biblioteca que posee el Cabildo de la catedral de San Cristobal de la Laguna fue donada según consta en el informe escrito de d. Andres Bello bibliotecario de la provincial de Canarias por el Arzobispo de Heraclea d. Cristobal Bencorno, natural de esta ciudad. Este prelado generoso hizo en vida aquel legado al cuerpo capitular. La procedencia de la biblioteca de que se trata, hace naturalmente suponer que la mayoria de los libros pertenecen a ciencias eclesiasticas, como en efecto es asi. El numero de volumenes que aparecen anotados en el catálogo es de 1308 y 195 cuadernos que hacen un total de 1504 cuerpos. Estos libros sin ningún genero de clasificación, constan todos del esperado catalogo o indice que no es mas que una simple lista, y aun asi bastante defectuosa. Contiene el título, lugar y años de las ediciones, pero no expresa el nombre de los impresores ni la forma, o tamaño de los volúmenes, ni hay tampoco ninguna nota biblográfica, biográfica, cientifica o literaria no pudiendose por tanto reunir en conocimiento del mérito de muchas de las ediciones hasta no tenerlas a vista. Tampoco aparece ninguna preciosidad bibliográfica, ni ediciones que daten antes de la

${ }^{24}$ Las repetidas e insistentes solicitudes del municipio para hacerse cargo y costear el mantenimiento de las bibliotecas de su ciudad para el servicio público, tuvieron su fruto, determinando concederles su petición en la sesión de 17 de abril de 1869. 
segunda mitad del siglo $16^{\circ}$. De manuscrito solo figuran un tomo de Sermones modernos, predicados por el Obispo de Astorga, d. Santiago Bencorno, hermano del Arzobispo donatario. Si hay algún otro manuscrito deberá estar entre los cuadernos, por lo cual deben estos examinarse con atención y cuidado.

Los defectos de que adolece el catalogo, impiden el conocimiento exacto de las obras que contiene, pero aun asi se ven muchas de relevante merito. Entre otras estan las Actas de los Santos, de los Bolando, colección muy apreciada, y que creo sea el unico ejemplar que hay en esta provincia; la magnifica edición de Salustio, traducido por el Infante D. Gabriel, obra que es ya muy dificil encontrar, y que por lo mismo tiene un alto precio en el mercado, una edicion de 32 S.S.P.P. griegos y latinos, que a juzgar por la data y los puntos de su impresion, debe ser de las ediciones de los benedictinos de San Mauro. Hay algunas otras obras de merito, pero que no exigen especial mención. Esta biblioteca pasará a formar parte de la provincial, juntamente con la de la Catedral de Gran Canaria, cuyo contenido se ignora por falta de indices.

\section{Castellón}

En esta provincia solo se han encontrado algunos cuadros, cuyo inventario se formó oportunamente, dejando aquellos en poder del Cabildo.

\section{Córdoba}

De las bibliotecas episcopal y capitular de Córdoba dice lo siguiente en su Informe el Comisionado Luis $\mathrm{M}^{\mathrm{a}}$ Ramirez y de las Casas Deza: Expulsados los jesuitas en 1767 dispuso el gobierno que los diocesanos recogiesen sus libros y formasen con ellos bibliotecas públicas.- En Córdoba se reunieron las librerias de Cordoba y Montilla y permanecieron sin arreglar hasta el pontificado de d. Agustin de Ayestaran y Landa (1796-1805), el cual con diseño que dio el arquitecto d. Juan de Villanueva construyo en el lado de medio dia del Palacio Episcopal una pieza de grande extensión a fin de que cupieran 22 grandes estantes de madera de Flandes, que alternan con grandes balcones acristalados, a uno y otro lado, por lo que no es posible hallar pieza mas adecuada para su objeto. Colocados los libros no se hicieron catalogos ni indices hasta el pontificado de d. Pedro Antonio de Trevilla, el cual doto dos bibliotecarios primero y segundo con el sueldo respectivamente de 8000 y 6000 reales, y fueron los primeros los doctores d. José de Hoyos Noriega y d. Jose de Medina y Gales. El número de volumenes era de 11 o 12 mil, de los cuales se encontraban muchos raros y curiosos y no faltaba obra alguna de las que deben ser el principal caudal de una biblioteca publica. Pero el año 1856 sufrio la sustracion de unos 400 volumenes de los de mas merito como que los escogio mano inteligente, siendo obispo el Sr. d. Juan Jose Bonel y Orbe, el cual supo esta ocurrencia y no procuro remediarlo.-Los estantes estan numerados y rotulados convenientemente y de ellos los tres primeros estan dedicados a letras humanas, y el cuarto derecho civil; el $5^{\circ}$ y el $6^{\circ}$ derecho canonico, el $7^{\circ}$ hasta el 17 inclusive cronicas eclesiasticas, el 18 y el 19 historia eclesiastica, el 20 historia profana, y letras humanas los dos ultimos. Los catalogos en dos tomos en folio y los indices en otros tantos tomos cuantas son las materias estan muy bien escritos y empastados.. A lo largo de la pieza hay varias mesas para los lectores que eran muchos en otro tiempo. Cerrose cuando al obispo le faltaron los diezmos de que salia la dotacion para 
el bibliotecario. Posteriormente aunque no se abria al público se ha cuidado de su limpieza y no ha mucho tiempo se hizo con este objeto una prolija operación. La biblioteca del cabildo se conserva en una pieza alta de la catedral. si todos los codices y libros que tuvo se hubieran conservado sería una de las mas interesantes de España, sino por el número de los volumenes por el merito de estos, puesto que se principio a formar en el siglo XIII y con los libros que en 1271 dono al Obispo d. Fernando de Mesa, cuarto Obispo de Cordoba, y asi en el cajon $\mathrm{n}^{\circ} 41$ segun el orden que tenia en otro tiempo, se notaba " donacion que el obispo d. Fernando hizo de su libreria a la Santa Iglesia de Córdoba. Este ejemplo fue seguido por otros obispos y capitulares. El Dean y Canonigo d. Pedro Ayllon,lego por su testamento otorgado el 3 de julio de 1303 una gran libreria que hoy dice el "doctor Feria en la Palestra Sagrada seria de gran estimacion si el destino no lo hubiese perdido". El obispo d. Fernando Gonzalez Deza hizo donación de su libreria al Cabildo el 20 de mayo de 1424, prohibiendo todo emprestito y enajenacion. d. Martin Fernandez de Angulo tambien Obispo de Córdoba en 1510 dono todos sus libros que eran muchos a la Santa Iglesia de Córdoba entre los cuales habia un tomo de epistolas y otro de oraciones que había hecho en justas publicas y en embajadas que habia desempeñado en las cortes de varios principes. Entre los libros de este prelado habia gran copia de M.S.S. griegos y arabigos y en otros idiomas. Aumentó igualmente esta biblioteca el chantre Anton Ruiz de Morales y el cronista Juan Giner de Sepulveda que dice en su testamento otorgado el 24 de marzo de 1564 " item quiero que los libros de mi libreria se repartan de esta manera: que los libros giegos, escritos de mano como impresos y todas las obras misas latinas, asi traslacion de Aristoteles, de Alejandro Aphrodiciense su comentador como lo que compuse de mi ingenio que estuvieren impresos y Plinio de Historia Natural, de marca grande, y tambien las obras de Platon y la tabla o indice de las obras de Aristoteles, todos estos libros se den a la Iglesia Mayor de Cordoba, a quien yo debo mucho y se pongan en su libreria para provecho de los hombres estudiosos". Otros sugetos hicieron asi mismo donaciones a esta biblioteca.- En vista de esto y de lo que conserva ha sufrido mucho menoscabo, asi por haber sufrido mucho menoscabo, asi por haberse inutilizado los libros, efecto de abandono, como por haberse sustraido libros, pues ya apenas se conserva algo de tanta riqueza; de lo cual se dice que en el reinado de Carlos III se sacaron muchos codices para la biblioteca del Escorial. De lo que hemos expuesto y del estado que ahora tiene se infiere lo mucho que ha perdido. Los libros que cuentan al dia estan colocados en estantes de escalerillas y se han limpiado recientemente por el canonigo encargado de ella. Los estantes que estan corridos en numero de 70, ocupan dos piezas de no mucha extensión. No existe ni un catalogo que dejo sin concluir el sabio penitenciario d. Manuel Maria de Arjona, y asi no se puede averiguar si han faltado algun libro desde aquella epoca. Se ha aprovado la agregacion de estas dos bibliotecas a la provincial.

\section{Coruña}

Catedral de Santiago. La biblioteca del Cabildo consta de 1600 volumenes que tratan en su mayor parte de Teologia, historia, derecho; se encuentran algunas impresiones del siglo XVI, pero la mayor parte pertenecen a los siglos XVII, XVIII, contando con algunos manuscritos sobre cuyo contenido no se ha dado todavia noticia.

Esta biblioteca pasara a formar parte de la universitaria de Santiago. 


\section{Cuenca}

Iglesia Catedral. Posee un archivo riquisimo que cuenta entre otros documentos algunos relativos a la Victoria obtenida en Lepanto, a la prision del obispo de Siguenza por el rey d. Pedro y otros que han de pasar a formar parte del Archivo Histórico Nacional. Tambien se ha incautado el Estado en esta Catedral algunos cuadros de gran valor, de los cuales unos se devolveran al Cabildo por estar dedicados al culto, y otros pasaran al Museo Provincial.

Uclés. La Orden de Santiago poseia en esta villa una Biblioteca muy importante, el archivo general y el llamado de Prueba de los cuales en epocas anteriores se han sustraido fraudulentamente y vendido en Madrid codices y documentos de gran valor. Lo que resta y ha podido salvarse de este abandono formara parte en lo sucesivo de nuestro Archivo Nacional.

\section{Gerona}

Iglesia Catedral. Entre los pocos libros que en esta se han encontrado hay dos codices preciosos, escritos en vitela y con una hermosa y bien conservada Biblia con policramatas, encuadernacion de terciopelo carmesi, con cuatro broches con cabos de plata dorada y un Evangelio de San Juan con figuras y dibujos alegoricos del Apocalipsis, encuadernacion tosca y algo deteriorada. Los cuales han de ser trasladados a la Biblioteca Nacional.

Tambien en las Iglesias de Lladó y San Juan de las Abadesas se han encontrado algunos pergaminos que pasarán al Archivo Historico de Cataluña si su importancia lo requiere.

\section{Granada}

En la Catedral de Guadix se ha encontrado una biblioteca de 1141 vol. correspondientes a 404 obras, 120 de Teologia, 180 de Jurisprudencia, 87 de Historia, 12 de Bellas Letras y dos de Medicina. Entre las primeras se cuentan ocho Biblias, 8 de S.S.P.P., 11 obras de Parenetica, 11 tratadistas, perteneciendo las demas a interpretes de la Sagrada Escritura y a Polemica. En Jurisprudencia 120 se refieren a la civil, que son en su mayor parrte obras de Derecho patrio Romano, casi todas de Comentarios y 60 se ocupan de Derecho Canonico. De las de Historia 52 tratan de profano y 35 de Sagrada.

Ninguna de estas obras se distinguen por su rareza o antiguadad y faltan trabajos sobre Ciencias Fisicas, escaseando mucho las publicaciones modernas. Mas aunque no se hacen notar por estos u otros caracteres interesantes, se encuentran algunas obras de reconocido merito literario y tipografico. Ediciones apreciables hechas ên Madrid en la Imprenta Real, Ibarra, Marin, Perez de Sota y en la de Monfort en Valencia. Obras en español ilustradas con grabados salidas de prensa de valia en Amberes y Bruselas.

Esta biblioteca pasará a formar parte de la Provincial de Granada.

Catedral y Capilla Real de Granada. Los archivos de estas dos iglesias son de escasa importancia. En la ultima se ha encontrado un armario donde se conserva la espada, cetro y corona de Fernando el Católico; un cofrecito en filigrana de plata en donde se 
dice guardaba la reina Isabel las joyas que enagenó para el viaje de Colon a las Americas, dos banderas de Castilla y dos estandartes bordados por Isabel I, y en el uno se lee "Tanto monta monta tanto Isabel como Fernando"; dos dalmáticas, una casulla un paño de altar y un misal manuscrito lindisimo que es una joya. Tiene este armario tres llaves, tiene una la comision de monumentos, por cuya razon y por la de exponerse estos objetos al publico en ciertas festividades, se han dejado donde estan.

\section{Guadalajara}

Alcala de Henares. En esta localidad se ha hecho la incautacion de los archivos, de la vicaria de la Magistral, que contiene papeles relativos a diezmos, concordias, pleitos, protocolos y otros papeles de escaso interes, y de la biblioteca del convento de Filipenses colocada en 50 estantes que contienen obras de teologia, predicables y otras comunes. Cuando se reciban mas detalles de aquellas y de esta se resolvera sobre el destino que se les debe dar. ${ }^{25}$

Pastrana. En al iglesia ex colegiata de esta villa se han encontrado hasta 527 libros en muy mal estado de conservacion y que pertenecieron al extinguido convento de Franciscanos.

Si su importancia lo merece seran trasladado estos libros al Instituto de Guadalajara.

Siguenza. En esta Catedral de Siguenza se ha encontrado una biblioteca, sino muy numerosa bastante importante por la fecha de las impresiones que pertenecen en su mayor parte al sigloXV, como se ve por el siguiente inventario:

Un libro del s. XV incompleto

Tres tomos Disputationes Teologicas, año 1670.

Libro impreso en el siglo XV, incompleto

Otro id.---------id--------------id.

Biblia Complutense, cinco tomos.

Juan de Jandun, sobre los libros de Aristoteles, 1485, impreso en Florencia.

Comentarios sobre el Libro de las Sentencias por Timoteo Veronente, cinco tomos.

Argumentos de la Menza, un tomo, 1513, por Antonio Luis Capolo, en los libros de las Sentencias, hacia 1484, 4 tomos.

Obras de Gerson, 1494, dos tomos.

Comentario de Lucio Apuleyo, 1497, un tomo.

Obras de Nicolas de Sicilia, Venecia, 1498, un tomo.

25 La incautación de los papeles del Archivo de la Iglesia Magistral de Alcalá, tuvo una contestación acalorada, que llevó a la Comisión a decidir la devolución a los antiguos poseedores, los documentos y efectos incautados en la Vicaría de aquella Magistral y parroquia de santa María, exceptuando los documentos históricos, libros y obras de fábrica, y los relativos a memorias y fundaciones. Respecto a la librería del convento de Filipenses se destinó ... a la biblioteca nacional y popular de la ciudad y al archivo general central. La lápida romana y sepulcro del suprimido convento de las Juanas debían llevarse al museo Arqueológico Nacional. 
Diccionario, un tomo.

Dos tomos de Historia de San Antonio.

Un tomo de Comentario de santo Tomas, Venecia, 1483

Un tomo de Retórica.

Exposicion Bíblica, Veda, un tomo.

Un tomo de Concilios Toledanos, 1459.

Estrabon un tomo.

Dos libros del siglo XVI, Tomas de Valois.

Un tomo de Teologia Moral, Roberto Holnot, del siglo XV.

Epistolas de San Pablo, un tomo imprso siglo XV.

Castillo, Cirugia, un tomo 1783.

Casos de Conciencia, un tomo, siglo XV, impreso en Bolonia.

Obras de San Bernardo, dos tomos, impresos en Leon, 1500.

Exposicion de la Tercera Parte de SantoTomas, un tomo.

Conclusiones Naturales de Marcos Gradonico, impreso en Venecia, un tomo, s. $\mathrm{XV}$

Sermones y Homilias, un tomo.

Breviario escrito por Francisco Pago, cuatro tomo.

Comentario sobre el Libro de las Sentencias, de Santo Tomas, cuatro.

Gildolfo de Virtudes, impreso en Paris, siglo, X?. Tres tomos.

Juan de Pico, un tomo.

Un tomo sobre Decretales, Venecia, 1497

Otro sobre las Clementinas, Venecia, 1497.

Bartolus, Super in for.dos tomos.

Tebas in Decretales, cuatro tomos Venecia.

Extravagantes, uno.

Felimus Lando, uno.

Valdo, tres tomos en Venecia.

Manuscrito, un tomo en folio.

Jamblyco, un tomo impreso,...tina, 1500.

Valencia, Comentarios en los Salmos, uno en 1482.

Coneriencias sobre Aristoteles, uno.

Sobre Comentarios de Santo Tomás, uno, Venecia, 1489.

Pedro Tilbaco sobre el Libro de las Sentencias, targel, 1490.

Obras de Luca, Venecia, 1726, trece tomos.

Reicenstuel, Derecho canonico, cuatro tomos

Torquemada, Suma de Celesia, uno en Lion, 1496.

Decretales manuscrito. 
Constituciones Clementinas, uno en Venecia 1486.

Pedro Bergonense, Obras, un tomo, Venecia, 1497.

Averroes, dos tomos Venecia, 1483.

Obras del repertorio del Abad, uno.

Suetonio, uno, en Venecia, 1498.

Novelas de Justiniano, un tomo, .

Juan Tusaris, un tomo, en Venecia.

Santiago Valatorrano, Milan, 1506.

Guillermo de Mandogato, manuscrito.

Pablo de Castro, sobre Concilios, Venecia, 1590.

Benedicto Plung, un tomo, impreso en Lessis, 1487.

Alberto de Gandino, un tomo, 1496.

Duanto, Repertorio, 1496.

Felipe Franco,sobre Decretales un tomo.

Un tomo manuscrito.

Patras, tercer libro de los codices, un tomo.

Imola un tomo, Venecia, 1496.

Casus Decreti, manuscrito, un tomo.

Gabriel Viel, dos tomos.

Santiago Valencia, sobre Escritura, dos tomos manuscrito.

Burleo, sobre los ocho libros de Fisica, uno.

Pedro Ciruelo, un tomo.

Decretales del Papa Inocencio, un tomo.

Andres Barbatia, un tomo, Milan, 1491.

Decretum, manuscrito, un tomo.

Comentarios un tomo.

Alberto de Segovia, un tomo.

Gregorio de Arimeno, un tomo

San Juan Crisostomo, un tomo.

Diego Deza sobre las Sentencias, un tomo.

Merlino, Comentarios sobre Origenes, un tomo.

Portilla, sobre los Salmos, Venecia, 1496.

Glosa, sobre la escritura, cuatro tomos.

Petro Tercense, sobre los Canticos, un tomo.

Tres tomos, colección de todas las Pragmaticas, Cedulas, Revisiones, Circulares, en el Reinado del Sr. Carlos IV.

Dieciseis sellos de plomo, de varias epocas.

Doce cuadros de las doce Sibilas. 
Cuatro cuadros que representan las cuatro estaciones.

Todos los libros de esta biblioteca seran trasladados a la Nacional de Madrid.

\section{Huesca}

Archivo de la Catedral. Por los indices de esta consta que tiene un numero considerable de pergaminos notables por su antiguedad, habiendo bastantes del siglo XI e inmediatos e incluso alguno del siglo $\mathrm{X}$, originales, con firmas o signos de los reyes de Aragon, refiriendose a privilegios, donaciones, etc, habiendo un numero mayor todavia de documentos originales y copias tambien de aquellas epocas, concerniente a la iglesia y obispado.

Tambien hay un codice notable que contiene la ilacion llamada del rey Wamba, en la que hace la división de obispados y arzobispados goticos del antiguo territorio de España, y a continuacion se halla la Biblia Laera, manuscrita, estendida en 942 hojas. Tanto la Ilacion como la Biblia se hallan escritas en pergamino, a dos columnas por pagina, cara y vuelto con 50 lineas en cada columna. La tinta negra, esistiendo algunas letras en encarnado: caracteres goticos algun tanto alterados.

Esisten tambien varios libros de estatutos y gobierno de la Iglesia. Legajos de cartas de iglesias y prelados en colecciones, Reales Cedulas, Cartas de Reyes y Ministros tambien en colecciones y otros muchos documentos, Bulas Breves, y papeles pertenecientes a la Iglesia, al dominio, y otros derechos que en heredades particulares tuvo el Cabildo.

Hay tambien muchos protocolos o notas de los escribanos que fueron de esta ciudad, Sres. Molino Gomez, Pilares y Blasco: ignoro si son los propios de la iglesia o si las escrituras en ellas protocolarizadas pertenecen al tuyo y mio de interes privado y forman la titulacion de su respectiva epoca en los contratos y transaciones de los particulares, pues en este caso y segun la legislación vigente debieran existir esos protocolos en el Archivo de Notarios de Huesca, al que desde luego conviene que sean trasladados. No obstante debe hacerse un examen detenido de ellos, para disponer con mas acierto de los mismos.

En el mismo Archivo se hallan los documentos pertenecientes a la Colegiata de Alquezar, incorporados por Reales Ordenes de 20 de diciembre de mil ochocientos sesenta y tres y 21 de julio del 64.

En el Archivo de la Colegiata de San Pedro el Viejo de Huesca, templo antiquisimo anterior a la reconquista y en cuyos claustros descansan las cenizas del Rey d. Ramiro el Monge y ahora las de d. Alfonso el Batallador, y las de otros insignes varones, segun muestran sus rotularios, aparecen algunos legajos de papeles pertenecientes a feudos y a otros derechos de la Iglesia.

Examinado el Indice del Archivo de la Catedral de Barbastro, aparece desde luego que no tiene la importancia que el de Huesca, se encuentran en el sin embargo algunas bulas, breves, y concordias y unos libros de coro trasladados a esta iglesia desde el Monasterio de San Victoriano.

Jaca. la biblioteca de la Catedral consta de 1736 volumenes, de los cuales treinta y dos pertenecen a Liturgias y Rubricas, 230 a Historia, 95 a Escrituras y expositores, 
148 a lecturas de recreo, 178 a lectura espiritual, 82 a teologia escolastica y Santos Padres, 185 a teologia moral, 946 a derecho canonico y civil, 196 a filosofia, 57 a clasicos, 71 a obras estrangeras, 74 a vidas de santos, 176 a sermones y 28 a sinodales y constituciones.

Aunque no ha recaido resolucion sobre el destino que ha de darse a lo incautado en Huesca, Barbastro y Jaca, parece natural que los libros se trasladen a la biblioteca provincial de Huesca, y los documentos y pergaminos al Archivo Histórico que se ha de crear en Zaragoza.

\section{Leon}

Biblioteca de la Antigua Colegiata de San Isidoro. Consta de 1680 vol. de obras impresas, la mayor parte del siglo XVI, llamando la atencion entre ellas una Biblia impresa en Venecia en el año1475, cuyas letras iniciales estan bellamente pintadas. Contiene ademas 59 codices entre los cuales sobresalen por su valor paleografico los siguientes: Biblia escrita en la era 968 o 970 por el presbitero Sancho, cuya fecha se halla al folio 490 vuelto. Tiene 492 hojas de pergamino y ademas dos en blanco en las que se admiran magnificas iluminaciones y viñetas, de admirable lujo respecto de su epoca, con figuritas a cuales mas simbolicas y caprichosas, su cubierta seforro recientemente de terciopelo azul cerrandose con broches de plata. Morales de San Gregorio, escritas en 352 hojas y letra española; su fecha es del año 951; Otra Biblia dividida en tres tomos del año 1162, letra gótica; Contiene preciosas miniaturas: el primer tomo tiene 194 hojas, el segundo 196 y el tercero 242; un breviario con buenas iluminaciones con 566 hojas de pergamino. Las obras de San Martino Diosdidas i en dos tomos. El primero contiene dos partes y la $1^{\text {a }}$ de estas 212 hojas faltan al final cuatro de ellas. La segunda parte tiene 196 hojas. El segundo tomo abraza la tercera parte en 292 hojas. Tan importante codice conserva perfectamente decoradas sus letras capitulares. Una copia de la cronica de España de D. Lucas el Tudense, con precedentes y recopilaciones a las de San Isidoro y San Ildefonso, Arzobispo de Toledo, sacada de orden de d. Juan $\mathrm{M}^{\mathrm{a}}$ Valenzuela, obispo de Salamanca, un codice escrito en papel, letra del siglo 14, que contiene las Meditaciones de San Agustin; Otra cronica del Tudense, letra toledana que fue copiada del original que existio en San Isidoro de leon, que fue llevado a otro sitio por los motivos que refiere el D. Haller en su Historia, en el folio111 del $2^{\circ}$ libro de ella. Un Martirologio del siglo XIII que no solo hace mencion de los santos de cada dia del año, si que tambien de los Reyes y personas Reales; Un codice en pergamino que contiene una traduccion hecha por J. Robles, canonigo de san Isidoro en el siglo 1525, de la obra del Tudense, e igualmente las maravillas de otro santo y la vida del canonigo San martino; Portillo Super Epistola paulo a fratre Nicolao de Lira. Codice en extremo raro, escrito en 1328; Los Decretales del Papa Gregorio IX, comentados y escritos en 1162; Las Partidas de Alfonso X , escritas en hojas de pergamino y papel mezcladas en el año 1343. Una Gramatica latina del año 1358, escrita en hojas de pergamino, es muy importante por su antiguedad y especial redacción. Cronica de d. Rodrigo. Esta obra esta escrita en papel y letra del siglo 14. Hay ademas un cajon lleno de revueltos documentos de pergaminos, muchos de ellos de gran valor historico pues son privilegios reales y donaciones que se remontan al siglo $\mathrm{IX}^{\mathrm{o}}$. Igualmente existe una porcion de legajos de manuscritos en papel y algunos en pergamino, que son en su 
mayor parte escrituras, sentencias y pleitos pertenecientes a la Colegiata de san Isidoro y su Iglesia. Entre ellos hay un mazo de bulas pontificias y ocho grandes cantorales.

\section{Objetos de arte de la Colegiata de San Isidoro.}

$1^{\circ}$. Una pila bautismal toscamente labrada en forma cuadrada con bajos relieves en sus cuatro frentes. Es interesantisima desde el punto de vista de la historia del arte, que en su epoca representa hallarse en bastante atraso, perteneciendo al estilo visigodo, tal vez anterior al siglo X. Procede de la parroquia de San Juan Bautista de origen remotisimo, reconstruida con ladrillo y barro por Alfonso V para panteon de los Reyes y de una grandiosa fábrica por d. Fernando I. En la que hoy reconocemos por la Real Colegiata de San isidoro sin que tanta transformación hayan felizmente hecho desaparecer la referida pila.

$2^{\circ}$. Una Cruz de marfil, riquisima joya de estilo bizantino, primorosamente tallada en su frente con alegorias y fantasticas figuras entrelazadas de follajes, obra de las mas interesantes y caracteristicas del siglo XI a que pertenece. En el frente esta dibujada la figura del Redentor, toscamente dibujada sujeta en cuatro clavos: en la parte superior de la cruz las inscripciones inc nazarenus rex iudiorum y al pie Ferdinandus Rex Sancia regina., lo cual testifica claramente su antiguedad y procedencia. En su reverso tiene en sus cuatro extremos los cuatro evangelistas representados por sus simbolos y en el centro el Cordero Pascual. Fue regalo hecho a la Regia Colegiata entre los muchos y preciosisimos con que los Reyes Fernando I y Dña. Sancha enriquecieron la Iglesia que acababan de edificar, segun consta en la carta de donacion dada por el dicho Rey con motivo de la traslacion a esta Iglesia de los restos de San Isidoro y en la que enumera las alhajas regaladas no menos que otras muchas donaciones y privilegios figurando entre los primeros la cruz referida. Por tradicion se dice ademas ser la que el referido Rey llevaba a las batallas. Su tamaño es de 58 centimetros de alto y 35 de ancho y conserva evidentes indicios de haber estado incustrada en oro.

$3^{\circ}$. Una caja de madera cubierta de chapas de marfil. Siete son las que cubren su frente, y cortados en cada uno de las cuales esta esculpido un angel y una figura alegorica a las bienaventuranzas; la figura asi como los arcos que las cobijan caracterizan perfectamente la epoca visigoda a que pertenece, siendo tal vez anterior a la cruz referida el $\mathrm{n}^{\circ}$ 2.- El respaldo de esta cubierta con trozos de marfil procedentes de cajas de estilo mudejar. A la siguiente vista del objeto que nos ocupa, se comprende ser de construcion no muy antigua, y que las chapas que la adornan son procedentes de otras mas interesantes que desgraciadamente han sido destruidos. Dificil es por lo tanto saber su procedencia, si bien debe de ser de alguna de las arquetas que refiere d. Fernando I en su carta de donacion ya citada. Sus dimensiones al presente son de 0'18 cts de largo por o' 13 de ancho y $0^{\prime} 16$ de alto. Contiene varias reliquias.

$4^{\circ}$.Una arqueta con reliquias de plata sobredorada y agatas. Distinguese este objeto por su sencillez, haciendo que su trabajo material no sea grande. Esta formado por franjas de plata de medio centimetro de ancho, las cuales se cruzan entre si por los bordes y centro formando recuadros, obalos y en los extremos arcos de herradura bastante pronunciados, presentando todo ello el mas perfecto estilo visigodo. Sus fondos sosn de agata color cafe. Su procedencia de la que ninguna noticia cierta existe tal vez sean como las anteriores. Sus dimensiones son 17 cts. de largo, 13 de ancho y 14 de alto. 
$5^{\circ}$. Otra arqueta con reliquias, de plata sobredorada y de estilomudejar, cubiertas de leyendas arabes, alternando con caprichosas grecas y con ricas bisagras de plata cinceladas. Ninguna noticia cierta se tiene de la procedencia de estos objetos, pudiendo suponerlos delos que los peregrinos y caballeros templarios traian a la Reina dña. Sancha, hermana del emperador D. Alfonso VII, devueltos de sus excursiones y que a su muerte dejo a la Iglesia de san Isidoro, pudiendo explicarse igual procedencia a las otras tres siguientes. Las dimensiones a las que se tratan son $18 \mathrm{cms}$. de largo, 18 de ancho y 18 de alto.

$6^{\circ}$. Una caja cuadrilonga con reliquias, estilo mudejar con leyendas al borde dela tapa y cuajadas espirales grabadas y entrelazadas entre si con visagras y cerraduras de plata cincelada con esmaltes. El material empleado en ella es plata y sus dimensiones $12 \mathrm{~cm}$. de largo por 0'08 de ancho $0^{\prime} 07$ de alto.

$7^{\circ}$. Otra id de plata con reliquias, estilo mudejar alternando con fondos de hojas de hiedra y franja con leyendas arabes. Su forma es ovalada de $0^{\prime} 11 \mathrm{~cm}$. de largo por $0^{\prime} 65$ de ancho y 0 '06 de alto.

$8^{\circ}$. Otra arqueta de madera cubierta de incustraciones de marfil y cuerno, formando entrelazados de ojas y luchas de fieras imaginarios y deformes, con leyendas alrededor de la tapa y herrajes de bronce de caprichosa forma. Su estilo mudejar y de 0'18 de largo, 0'13 de ancho y 0'11 de alto.

$9^{\circ}$. Un relicario de plata sobredorada. Componese de un prisma de $0^{\prime} 6 \mathrm{~m}$. de alto cuya base es un exagono regular, formando la tapa una piramide de igual forma.

Relacion de los libros y otros objetos hallados en unos cajones que los Jesuitas de San Marcos de Leon dejaron en una casa de esta ciudad, de los cuales se hizo cargo el Sr. Gobernador de esta provincia..- Cinco mil cuatrocientos quince volumenes de obras impresas y mas de mil folletos que tratan de importantes materias. cinco manuscritos a saber: una copia en italiano de la vida de Santa teresa hecha recientemente; una relación de los Abades que fueron al Monasterio de Sandoval con notas curiosas; Dos documentos escritos en pergamino: uno ejecuta confirmacion y privilegio del Rey d. Enrique $4^{\circ}$ concediendo al monasterio de Sandoval el tener diez criados libres de pagar todo pecho, fonsaderas, moneda etc. Esta fechado en el año de 1459. El otro es un Privilegio del Papa Inocencio $1^{\circ}$ concediendo a dicho convento y sus Abades varias preminencias. llevan sellos de plomo pendientes.- Manuscrito en papel que contiene una confirmacion de los privilegios de la Orden, a favor del Abad de Sandoval, dada en Valladolid por la Reina Catolica en 1481; Un metodo de musica para piano por I. ¿? Ultimamente un cajon que contiene minerales y una cajita con figuras de madera para el estudio de la geometria.

Procedentes del mismo Colegio de Jesuitas se han encontrado tambien y entregado al Instituto de Leon cinco bultos que contienen diferentes efectos de botanica, zoologia y mineralogia, y cuatro que contienen aparatos de fisica y quimica, un monetario, un gasometro, una maquina electrica, sin disco, una maquina de Aiwod, una caja de insectos, un aparato para el choque de los cuerpos sin bola de marfil y un anteojo celeste y otro terrestre. 
No se ha resuelto todavia el destino que debe darse a los ricos y preciosos objetos de esta provincia, esperando si tener colocacion comoda y segura en el monumental edificio de San Marcos.

\section{Lerida}

Se esperan mas datos sobre el resultado de la incautacion en esta provincia.

\section{Logroño}

En las Iglesias de Santa Maria de la Redonda y de Santa Maria de Palacio se ha incautado el Estado de algunos cuadros y libros, que se devolveran en su mayor parte al Cabildo, por estar afectos al culto.

\section{Lugo}

El Archivo de la catedral de Lugo no contiene papeles de grande interes historico, a juzgar por los inventarios que de los mismos se han remitido, por lo tanto seran devueltos al Cabildo tan luego como se haga su clasificación.

En la catedral de Mondoñedo se ha incautado el Estado de un báculo de bronce, con esmaltes y piedras del siglo XII, y unas sandalias o zocos de la misma epoca, y de unos altos relieves en alabastro que representan pasages de la vida de la Virgen, procedentes tal vez del primitivo retablo del altar mayor o de la antigua capilla de la Trinidad, cuyos objetos han sido reclamados con destino al Museo Arqueologico Nacional.

\section{Malaga}

Se esperan mas datos sobre el resultado de la incautacion en esta provincia

\section{Murcia}

En la Iglesia Catedral de Murcia y en las iglesias y monasterios de la ciudad de Lorca, se han encontrado algunos cuadros y objetos de arte, que seran entregados a la comision de monumentos de la provincia, exceptuando unicamente aquellos que esten afectos al culto.

En la iglesia de Cartagena se han encontrado dos capiteles bizantinos, una campana desmontada y sin uso con inscripciones goticas y monacales, siete bajos relieves de alabastro sobre asunto de la historia sagrada y de epoca remota algo mutilada, cuyos objetos se han reclamado con el destino del Museo Arqueologico Nacional.

\section{Navarra}

En la catedral de Pamplona se ha encontrado una biblioteca que contara de unos 7956 volumenes, de algun valor y merito al decir del comisionado.

En la Colegiata de Roncesvalles hay tambien otra biblioteca que contara con unos 7900 volumenes, segun el calculo que forma el comisionado. plona.

Se ha propuesto formar con estas dos riquisimas bibliotecas una pública en Pam-

Tudela. El Archivo de la Catedral de Tudela contiene importantes documentos como puede verse y de los que informa el comisionado y son 
$1^{\circ}$. Copia y su original del que penden tres sellos del gran prior de Navarra, del Comendador Mayor, del Prior dela Iglesia tudelana, contiene una sentencia dada por el Comendador Mayor del Hospital Jerusalen, condenando al Rey D. Teobaldo de Navarra a pagar al Cabildo de Tudela los diezmos de los frutos que dicho Rey seguia en sus heredades.. Data del año 1235,- Cajon $n^{\circ} 1$ letra $S$.

$2^{\circ}$. Subsidio que se pago al emperador Carlos $\mathrm{V}$ de 71 y un ducados de oro viejo, por el Cabildo de Tudela. Data del año 1541. Cajon n ${ }^{\circ} 3$ - letra S.

$3^{\circ}$. Absolucion para los que hubieran ayudado al Rey d. pedro de Aragon en la tenencia de los Reinos de Sicilia, consentida por el Papa Martino 10 al Arzobispo de Zaragoza. Data del año 1291. Cajon $\mathrm{n}^{\circ}$ 5, letra A

Item la misma absolucion consentida al obispo de tarazona. Año de 1295. Cajon $\mathrm{n}^{\circ}$ 5. Letra A.

$4^{\circ}$. Bula del Papa Nicolas IV al Arzobispo de Tarragona y sus sufraganeos, en que pide favor para que el Rey pase a Tierra santa. Fecha de 1295. Cajon $\mathrm{n}^{\circ} 5$ letra B

$5^{\circ}$. Item comision del Papa Nicolao 10 para absolver al cabildo de Tudela y a todos los que con el Rey d. Pedro de Aragon contravinieren a las letras de d. Martin IV sobre la posesion del reino de Sicilia, año 1291. Cajon $\mathrm{n}^{\circ} 5$ letra C

$6^{\circ}$. Cadenas de Navarra donadas a esta Iglesia por el Sr. Rey Sancho VIII ${ }^{26}$, que existen colocadas al lado del Evangelio del Altar Mayor. Data del año 1194. Cajon $n^{\circ}$ 5. Letra $\mathrm{C}$.

$7^{\circ}$. Fueros de Cedulas concedidas por el Rey D. Alfonso el Batallador cuando la conquisto. Data de 1114. Cajon $n^{\circ} 5$ letra D

$8^{\circ}$. Testamento del Rey d. Theobaldo de Navarra por el que funda en Santa Maria de Tudela un aniversario de 50 sueldos y 20 para la celebracion de la fiesta de santa Ana, patrona de esta ciudad. cajon $\mathrm{n}^{\circ} 8$ letra $\mathrm{E}$.

$9^{\circ}$. Absolucion para el Condestable de Navarra por haber muerto al Obispo de pamplona D. Nicolas de Chavarri.- año 1480.Cajon $\mathrm{n}^{\circ}$ 13. Letra A.

10. Cedula de su Majestad por el cual declara exento de sorteo para el remplazo del ejercito a todos los musicos de plaza sentada y asalariados de las catedrales e iglesias de estos reinos, tanto de voz como de instrumento, en la forma que contiene.Año 1770. cajon $\mathrm{n}^{\circ} 9$ letra $\mathrm{C}$

11. Trasunto de testamentos del Rey d. Alfonso y otros Reyes desde el año 1062 hasta el de 1209. Cajon $\mathrm{n}^{\circ} 15$. Letra E.

12. Una Biblia manuscrita en $4^{\circ}$ de marca, en vitela con caracteres hebreos.

13. Un tomo en folio de vitela donde esta escrita e iluminada la historia del Apocalipsis, tambien manuscrita. Le faltan algunas hojas al principio y al fin algunas laminas.

26 En nota del documento: "El inventario dice Sancho VIII pero sin duda alguna es Sancho VII apellidado el Fuerte". 
14. Un Breviario manuscrito en vitela en $8^{\circ}$.

15. Un martirologio en folio, escrito en vitela. se presume ser el de Ugardo porque comienza “ Domino Regum Piisimo Carolo Guardus, magnus Lacerdos Acomonachos perhenem in Christum coronam.

16. Unas Decretales y un libro iluminado con algunas letras de oro impresos en Roma en 11.. en folio. Hay un pergamino en las fundaciones de aniversarios por el que consta haber sido tasados en 40 florines de oro.

17. Anales del Reino de Navarra, escritos por el Padre Jose Moret, cinco tomos en folio; hay otro libro de investigaciones historicas todos ellos se hayan en el segundo cajon grande que estaba debajo del de los pergaminos.

Todos estos documentos estan destinados al Archivo Historico Nacional.

\section{Palencia}

[falta]

...Nacional tan luego como se estudien mas detenidamente.

En las iglesias de Aguilar de Campoo, de San Salvador de Cantamuga y en la Colegiata de Ampudia, se han encontrado algunos documentos y objetos de arte, sobre cuyo destino no ha recaido todavia solucion.

\section{Salamanca}

La biblioteca del cabildo contiene bastantes libros que tratan en su mayor parte de Derecho Canonico y Teologias. El Archivo encierra privilegios rodados de los Reyes de Leon y de los de Castilla, a favor de esta iglesia, alguna carta puebla, Ejecutoria que gano el Cabildo en algunos pleitos y otros instrumentos, escritos todos en vitela, con letras capitales, orlas, miniaturas y escudos reales, iluminados con oro y colores, hay tambien una coleccion de cartas originales dirigidas al Cabildo por los Reyes Catolicos y por Carlos I Felipe II y III, con sus firmas autografas, con dos o tres buenos codices, escritos en vitela con horlas y miniaturas iluminadas.

En el Convento de Santo Domingo, hoy parroquia de San Pablo hallo la subcomision una hoja de espada de siete palmos de longitud, sin puño ni vaina, metida en el hueco de una pared, por esto y por el tiempo oxidada toda, segun la tradicion del convento de $\mathrm{d}$. Juan de Austria en la batalla de Lepanto y tuvo hasta la guerra de la Independencia ( al decir de los individuos de las subcomisiones que la vieron entonces) una rica empuñadura de oro y piedras preciosas, que desaparecio. Dicese ademas que la regalo a la Virgen del Rosario, en cuyo relicario se haya un Duque de Alba pariente del fundador del convento, como memoria de haber dado la batalla en el dia de aquella festividad.

Entre los objetos artisticos de la misma Catedral, se ha encontrado un precioso modelo de Tabernaculo, ejecutado con maderas finas en Madrid a finales del siglo anterior, bajo la direccion del arquitecto D. Manuel Martin Rodriguez, director de la Real Academia de San Fernando, y sobrino, alo que parece del celebre d. Ventura Rodriguez. Es en verdad una obra acabada en su genero, de estructura clasica, con bellas estatuas y otras esculturas, y tallas de buen gusto y primorosa ejecución. Tuvo de coste 
el Cabildo 65.311 reales, y el presupuesto de su ejecucion es grande, con marmol y bronces, para colocarlo en el crucero de la Catedral nueva, bajo la cupula o media naranja montaba la suma de 1. 156. 554 reales. Guardalo el Cabildo en una de las piezas del su Archivo, sobre una mesa y cerrado con bastidores. Este modelo se ha mandado entregar a la comision de monumentos de la provincia.

Por ultimo, en el Convento de las Dueñas se han encontrado algunos libros corales, que se cree proceden del Convento de Santo Domingo.

Todos estos objetos quedaron en la localidad, salvo alguno notable y raro, que se destina a alguno de los establecimientos nacionales.

La espada de d. Juan De Austria se ha entregado al Ministerio de Marina para que figure en su Museo.

\section{Santander}

El comisionado de esta provincia d. Antonio Felix Garcia, canonigo de aquella Iglesia Catedral, dio en su Informe lo siguiente:

Excmo. Sr. Ministro de Fomento= Nombrado por el Sr. Gobernador de esta provincia como comisionado para la incautacion a nombre del Estado del Archivo y Biblioteca que estaba a cargo del Cabildo de la Catedral, a la vez que tengo el honor de informar a V.E. de la traslacion y gastos que ocasiono lo incautado voy a permitirme referir algunos antecedentes que comprueban el posible abandono al par que la arbitrariedad y la injusticia con que han procedido, no tan solo el cabildo, sino tambien el $\mathrm{Sr}$. Obispo de Santander, el M. Rvdo. Arzobispo de Burgos, su Provisor y el Tribunal de la Rota de la Nunciatura $=$ Asi que tome posesion de canonigo de esta Catedral, reclame en el año de 1864 la observancia de los Estatutos que disponen haya un archivista y se nombren cada año visitadores de los libros y papeles de contaduria y secretaria, porque no pudo menos de sorprenderme el desorden en estaban estas dos oficinas, y la inexplicable anomalia de que el archivo estuviera cerrado con tres llaves, y ocultos sus documentos a todo examen o inspeccion, sin permitir siquiera entrar a los mismos canonigos. Pero mis justisimas pretensiones no solo fueron desatendidas, sino que recayeron acuerdos del cabildo prohibiendo que ningun capitular pudiera tomar notas ni aun leer ni examinar documentos. Hice presente al superior jerarquico inmediato tanta arbitrariedad e injusticia y ni siquiera se ha dignado decretar mi escrito. Produje despues queja al M. R. Arzobipo de Burgos por la negligencia y retardo malicioso en resolver el sufraganeo y se excuso de conocer gubernativamente. Entable recurso en el Proviorato de Burgos y fue desestimada. Por ultimo apele al Tribunal de la Rota y publicandose en tanto el Decreto de refundicion de Fueros solicite que en conformidad a la disposicion $1^{\mathrm{a}}$ transitoria pasara el Expediente a la Audiencia de Burgos. Mas ha sido inutil, porque el Auditor Fiscal de la Rota ha informado que el parrafo $1^{\circ}$ del articulo $1^{\circ}$ del Decreto reconoce la necesidad de la sancion pontificia para la validez de los actos jurisdicionales, y por consiguiente significa que la resolucion queda en suspenso, hasta se verifique el acuerdo con el Santo Padre.

He aqui erigido en terna para la impunidad el privilegio y esencion de que se hallaban revestidos los eclesiasticos, segun muy oportunamente exponia al fin del preambu- 
lo del Decreto de 6 de diciembre el Sr. Ministro de Gracia Y Justicia $=$ Hecha esta sucinta historia de la infraccion por el Cabildo Catedral de las constituciones mismas porque se rige y de los abusos del poder eclesiastico, soy del parecer que se trasladen todos los documentos del Archivo y de la secretaria y contaduria, lo mismo que los libros de la biblioteca, a un local que podra proporcionar el Sr. Gobernador en el edificio que ocupa de la Aduana, toda vez que el sitio en que hoy estan colocados es el que sirve de sala de sesiones y secretaria del Cabildo.= Los Indices asi del archivo como de la biblioteca, no pueden suministrar datos bastantes porque estan hechos en el año de 1794, y con las leyes de desamortizacion de la riqueza material habran pasado documentos a las oficinas de Hacienda Publica. Poe eso deben examinarse los documentos del Archivo porque algunos perteneceran a la Hacienda e interesaran a su Administracion.

Se ha propuesto la creacion de una Biblioteca publica en Santander si el numero de volumenes incautados hace conveniente esta medida.

En la Iglesia de Santillana se han encontrado algunos pergaminos en numero de 78, los cuales seran trasladados a la capital.

\section{Segovia}

El Archivo del Cabildo de esta Diocesis del cual se entregaron, ya en 1841, para los efectos de la desamortizacion gran numero de legajos, se haya hoy en un estado de completo abandono y desorden; por casualidad se haya un estante cuyo rotulo convenga a los legajos que contiene; muchos de estos estan esparcidos y desparramados por el suelo: el polvo que en este estado los cubre indica que el abandono data de atrasada fecha y a la verdad no se concibe como pueden hallarse los documentos que frecuentemente se necesitan acerca de capellanias, patronatos y otras fundaciones piadosas en aquel monton informe de papeles; no mas ordenados pero si mejor colocados se ven algunos legajos de musica antigua, alguna original; y lo mismo puede decirse de la colocacion de libros, que cuenta con unos 500 volumenes.

Los documentos del Archivo pueden clasificarse en seis grupos de la manera siguiente:

$1^{\circ}$. Documentos concernientes a fundaciones piadosas: de estos la mayor parte se refieren a epoca moderna no pasando mas alla del siglo anterior y no creo tengan valor alguno para la historia.

$2^{\circ}$. Los que se refieren al servicio interior de la misma iglesia catedral, asistencias, reparticion de cargos, distribuciones etc.

$3^{\circ}$. Los llamados de fabrica, que se hallan en completo desorden, con manifiestos indicios de haber sido registrados en repetidas veces; en ellos podrian encontrarse algunas noticias curiosas, referentes en especial al corte de todas y cada una de las partes del edificio catedral y objetos propios de culto.

$4^{\circ}$. Legajos de musica, vulgarmente llamados villancicos.

$5^{\circ}$. Libros encuadernados asi manuscritos como impresos, entre ellos algunas ediciones del siglo XV y principio del XVI. Se hecha de menos el manuscrito de Danis sobre vidriera y cristalina imaginaria, asi como la Farsalia de Lucano y 
aunque pueda asegurarlo tambien falta el Herculano: Estoslibros se hallaban no hace muchos años en dicho Archivo, segun aseguran personas entendidas, conocedoras del mismo.

$6^{\circ}$. Planos originales de la Santa Iglesia Catedral.

Entre los objetos de arte y alhajas nada hay que no sea aplicable al culto, sin embargo merece mencionarse un caliz del siglo XV y una colecion de tapices flamencos.

Los tapices flamencos, los documentos marcados con $\operatorname{los} n^{\circ} 2^{\circ}, 4^{\circ}, 5^{\circ}, 6^{\circ}$, seran trasladados a Madrid, exceptuando los libros impresos comunes que han de pasar a aquella biblioteca provincial.

\section{Sevilla}

Se esperan mas datos sobre el resultado de la incautacion en esta provincia

\section{Soria}

El Archivo de la Iglesia colegial de San Pedro de esta ciudad contiene documentos de escaso interes. Hecha la confrontacion del inventario de las alhajas del Cabildo encontrado en el Archivo con los efectos que dicho inventario se consigna se noto la falta de los objetos que se expresan a continuacion:

Una llave de oro para la urna del monumento

Una custodia dorada de plata

Un atril con chapado de idem

Dos misales con cantoneras de idem.

Cuatro cetros de idem.

Un incensario de idem.

Una cruz chapada y afiligranada de idem.

Una campanilla de idem.

Un hisopo de idem.

Una Virgen del Pilar de idem.

Una reliquia de San pedro de idem.

Un Lignum Crucis de idem.

Una concha de crismeras, de idem.

Dos coronas de la Virgen del Pilar de idem.

Dos relicarios con los casquillos de idem.

\section{Tarragona}

En la Iglesia Catedral se han encontrado algunos cajones que contenian en revuelta confusion momias y osamentas de los Reyes de Aragon, sin Catalogo ni Indice alguno, los mismos que trasladados de Poblet existian depositados desde algunos años en una pieza contigua al Archivo: la mas importante de ellas es un cajon en que se hayan depositados los restos de d. Juan II y dña. Juana su esposa, y de varios infante, recogidos 
de su saqueado y profanado sarcofago por el Sr. Hernandez, uno de los firmantes que los recogio en el Monasterio de Poblet a ultimos del año 1855, cuando como inspector de antiguedades, se le comisiono para transportar el sepulcro de d. Jaime I de Aragon. Estos ultimos restos se hayan depositados en una caja, y dentro de la misma hay parte de la momia del celebre Principe de Viana, recogida por el firmante.

El Archivo del Cabildo y de la suprimida comunidad de Beneficiados contienen papeles importantes que seran trasladados al Nacional, juntamente con los pergaminos que se han encontrado en las oficinas de desamortizacion de la provincia.

\section{Teruel}

En esta provincia se ha incautado la nacion de la Biblioteca Episcopal, y del Archivo de la catedral, como tambien del de la Iglesia de Alcañiz, sin que se halle remitido todavia el Indice de su contenido.

\section{Toledo}

Vease la memoria

\section{Valencia}

Vease la memoria

\section{Valladolid}

En el Archivo de la Catedral se han encontrado 31 legajos con documentos y vitelas con sellos dignos de conservarse, y 277 volumenes que se refieren a la Administracion y Contabilidad del Cabildo. Hay dos retratos uno de d. Pedro Ansurez y otro de d. Juan Leiva ; Ademas 189 volumenes impresos que tratan de ciencia s teologicas, medicina etc. Que en la sala capitular hay 98 cuadros alguno de ellos de bastante merito, sobre todo el de la Anunciacion, atribuido a Jordan. En la biblioteca hay 2998 volumenes que tratan de filosofia, de derecho civil y canonico etc. entre los que existen libros de grande importancia literaria y venerable antiguedad. El comisionado propone que se trasladen a la biblioteca provincial. A continuacion describe los cuadros, en numero de 45, que existen en la nave de la iglesia. En el Hospital de Santa $\mathbf{M}^{\circ}$ de Esgueva se han encontrado 91 volumenes de derecho e historia, un arca con 78 pergaminos y dos cajas que contiene los guantes y espada que usaba el fundador, el conde $\mathrm{d}$. Pedro Ansurez. En la sala de Juntas se conserva un retrato de este conde. En el convento de Santa Clara se ha encontrado una cajita de pino con 72 vitelas de los siglos XV a XVI, que conserva el vicario de las monjas. Existen tambien 37 pinturas de escaso merito. En el convento de las Huergas se han encontrado 95 pinturas, algunas de merito, y en el centro de la Iglesia esta el convento de dñ ${ }^{a} \mathrm{M}^{\mathrm{a}}$ de Molina, con una estatua yacente que la representa. En el convento de las monjas Claras de Tordesillas se han encontrado multitud de legajos y papeles referentes a arrendamientos, rentas, etc. existen tambien 84 pinturas de escaso merito. Con respecto a los cuadros propone el comisionado que se trasladen a los Museos Nacionales.

Medina del Campo. En el Archivo de esta Iglesia se conservan multitud de papeles en completo desorden, y 70 cajones que contienen escrituras, obligaciones etc. de aquella abadia. En la biblioteca hay 2253 volumenes de importancia literaria, proce- 
dentes en su mayor parte de los Jesuitas. El comisionado propone la creacion de una biblioteca local, a cuyo objeto el Ayuntamiento proporcionaria un edificio conveniente. Reseña luego algunas pinturas y esculturas de la Iglesia. En el Hospital de Simon Ruiz se encontraron 6 baules llenos de libros, en mal estado de conservacion procedentes de algunos de los conventos extinguidos y en el Archivo una porcion de legajos entre los que hay 9 bulas pontificias. En la Sacristia hay una escultura obra de un artista Americano del tiempo del descubrimiento del Nuevo Mundo. El Alcalde de Aguilar del campo dice: que los pocos papeles que había alli pertenecientes a las parroquias, se remitieron a la contaduria de la provincia en el año 1842.

Se ha propuesto la traslacion a la Biblioteca y Museo provincial de todos los impresos y objetos de arte, y que se trasladen al Archivo Nacional los 31 legajos del Archivo de la Catedral.

\section{Vizcaya}

Nada se ha encontrado en esta provincia que sea objeto del Decreto de Incautacion, cuyo hecho explica en un Informe el comisionado de la misma de la manera siguiente:

Situada en un rincon de la Peninsula; separada de todo contacto con los pueblos mas civilizados; con leyes costumbres e idiomas especiales:= agreste y pobre por naturaleza, eminentemente montañosa, diseminada su poblacion en pequeños valles y vericuetos, cuyo caserio trae a la memoria la forma de la constitucion de las primitivas sociedades; pueblo pastor y navegante en sus remotos tiempos, mas tarde guerrero y agricultor y posteriormente industrial y mercantil, pero conservando siempre su forma de gobierno y la estructura de sus poblaciones; sin mas historia que la tradicion, sin mas gobierno que el fuero de albedrio; sin mas leyes que las recopiladas en su codigo del siglo XV; poco apegado a las innovaciones modernas; refractario por instinto a todo lo que no dimane de si propio; libre, independiente y altivo y tenaz como ninguno acaso en la defensa de sus inmunidades y franquizias, ni conocio en lo antiguo la ilustracion de los pueblos invasores, ni dio acogida en la Edad Media a los progresos de algunos conocimientos que ya en esta epoca despuntaban, ni quiso admitir mas tarde las teorias de las ciencias modernas.

Un pueblo asi constituido no podia fundar esos suntuosos edificios en que se albergaba particularmente el saber humano; y como carecia de congregaciones monasticas, las cuales a no dudar coadyubaron eficazmente al desarroyo de las bellas artes enriqueciendo con otras de subido merito sus bovedas y galerias, sus bibliotecas y archivos, jamas poseyo ni esos monumentos ni esas obras inestimables que para desdoro de los españoles han desaparecido en estos ultimos tiempos de la sobreal [i] de sus dominios.

Los mas antiguos conventos de Vizcaya se remontan no mas alla del siglo XIV, ni sus iglesias propiamente dichas, salva alguna rara excepcion. Habia, si, en esta tierra, la ermita, el ermitorio, la Capilla, en epocas que se rozan con la aparicion del cristianismo, simples edificios de cuatro paredes con su tosca espadaña y el signo de la Redencion del Señor por remate. pero la Iglesia del monasterio, la abadia, el convento, el suntuoso y amplio templo catolico, no aparecieron hasta la fundacion de las villas por los señores vizcainos. Y este hecho tiene una natural explicacion. 
V.S. sabe que las anteiglesias que son el infanzonado o tierras llanas de Vizcaya se compone de caserias dispersas en grandes jurisdiciones, y que de trecho en trecho o en las juntas mas a proposito para el trafico y de mejores condiciones higienicas se agrupan pequeños numeros de casas que forman simples barriadas. Proximas a estas casas se halla la Ermita, que constituye por decirlo asi parte integrante de la barriada, y el santuario que separado totalmente de ella se eleva en lo mas encumbrado de nuestros riscos y sierras. El primero como el segundo sirve para el culto catolico: aquel para los usos mas ordinarios y frecuentes, este para la peregrinacion o romeria que el pueblo vizcaino consagra en señalados dias del año al santo que en el se venera. Estos pueblos, como todos los que arrancan de un origen patriarcal y no han perdido sus costumbres, construian para mayor comodidad de su vecindario varias ermitas, pero no iglesias, porque pobres de suyo, y separado su vecindario por larguisimas distancias, no contaban, como no cuentan hoy, con recursos bastantes para construir suntuosos edificios. Las villas, que datan de los siglos XIV y XV, fundaron algunos de estos, asi como tal cual convento, pero de riqueza escasa y sin relevante merito artistico.

Por estos breves apuntes podia V.S. que un pueblo que carece de toda clase de monumentos antiguos, que no posee nínguno moderno de verdadera importancia, que jamas tuvo catedral, abadia, monasterio ni templo alguno de valor realmente artistico, no podia encerrar en sus archivos esas preciosidades que han atesorado y todavia atesoran otros muchos de los que se abren en la mayor parte de las ciudades de alguna importancia de la península, y que por consiguiente sería inutil el objeto que se propone el Decreto del Sr. Ministro de Fomento.

Hay ademas otra razon que corrobora lo que acabo de exponer. Si en algun tiempo pudieron encerrar los conventos $u$ otras fundaciones analogas de Vizcaya algun libro curioso u objeto artistico, todos ellos desaparecieron durante los siete años de la última guerra civil. Estos edificios dedicados al culto catolico antes de la ya citada guerra, fueron transformados en fortalezas por los dos bandos que lucharon con demasiada tenacidad y empeño hasta el convenio de Vergara. Inutil es recordar a V.S. los estragos que producen las guerras y la soldadesca posesionada a viva fuerza de un edificio cualquiera. Los conventos y algunas iglesias de Vizcaya fueron derruidos, incendiados o arrasados a flor de tierra, si alguno pudo salvarse y contuvo algun objeto de escaso merito, este fue trasladado al instituto vizcaino. 